\title{
DEVELOPMENT OF COLLAPSE-CONSISTENT LOADING PROTOCOLS FOR EXPERIMENTAL TESTING OF STEEL COLUMNS
}

\author{
Yusuke Suzuki ${ }^{1}$, and Dimitrios G. Lignos ${ }^{2}$ \\ ${ }^{1}$ Nippon Steel Corporation, Japan \\ ${ }^{2}$ Resilient Steel Structures Laboratory (RESSLab), École Polytechnique Fédérale de Lausanne (EPFL), Switzerland
}

In order to effectively utilize results from quasi-static cyclic testing on structural components for the earthquakeinduced collapse risk quantification of structures, the need exists to establish collapse-consistent loading protocols representing the asymmetric lateral drift demands of structures under low-probability of occurrence earthquakes. This paper summarizes the development of such protocols for experimental testing of steel columns prone to inelastic local buckling-induced softening. The protocols are fully defined with a deformation- and a force-controlled parameter. They are generally applicable to quantify the capacity and demands of steel columns experiencing constant and variable axial load coupled with lateral drift demands. Through rigorous nonlinear earthquake collapse simulations, it is found that the building height, the column's local slenderness ratio and ground motion type have the largest influence on the dual-parameter loading protocol indexes. Comprehensive comparisons with measured data from fullscale shake table collapse tests suggest that, unlike routinely used symmetric cyclic loading histories, the proposed loading protocol provides sufficient information for modeling strength and stiffness deterioration in steel columns at large inelastic deformations.

\section{KEYWORDS}

Loading protocols; collapse assessment; steel columns; deterioration modeling; axial load variation

\section{INTRODUCTION}

With the advent of performance-based earthquake engineering (FEMA 2012) the need for collapse margin quantification of structures beyond the design-basis earthquake has become apparent. This is acknowledged in current standards (ASCE 2016) so as prospective designs can achieve a tolerable probability of collapse at a given seismic intensity. It has also become a necessity for the development of building seismic performance parameters in new earthquake-resistant lateral load systems (FEMA 2009a). Collapse risk assessment relies on the use of numerical models (Ibarra et al. 2005; Krishnan 2010; Sivaselvan 2013) simulating deterioration characteristics of structural components under cyclic loading. In turn, these models rely on experiments that should ideally represent a component's hysteretic behavior at large inelastic deformations associated with collapse (Lignos and Krawinkler 2011, 2013).

A common practice for experimental testing of steel components has been the routine use of symmetric cyclic loading protocols (Krawinkler 1996; Krawinkler et al. 2000a; Richards and Uang 2006). These were originally developed to establish acceptance criteria for steel beam-to-column connections subjected to a design-basis earthquake (i.e., $10 \%$ probability of exceedance over 50 years). During the design-basis seismic event, steel moment-resisting frames (MRFs) exhibit modest lateral drift demands (i.e., 1.5\% or less) with practically zero mean (residual) effects. Therefore, the additional symmetric loading cycles with larger drift amplitude reversals (above 1.5\%) is an arbitrary decision of the experimentalist. This, in most cases, leads to an overly conservative estimation of the seismic demands observed in frame structures (FEMA 2009b).

Backbone curves for component modeling and acceptance criteria, according to today's seismic assessment standards (ASCE 2017; NIST 2017), are based on envelope curves fitted to hysteretic data from tests that relied on fully symmetric loading protocols. Research (Lignos et al. 2011, 2013; Mergos and Beyer 2014; Suita et al. 2015; Nojavan et al. 2015) and field observations from past earthquakes clearly demonstrate that the above protocols do not reflect the seismic demands incipient to collapse. In reality, the seismic response of structural components is characterized by relatively few symmetric cycles and a tendency for a structure to drift in one loading direction. In this case, symmetric deformation reversals become somewhat irrelevant (Krawinkler 2009; Lignos et al. 2011). Moreover, symmetric loading histories do not necessarily provide pertinent deterioration characteristics for collapse modeling of 
structural components (Haselton et al. 2008; Lignos et al. 2011). The reason is that they do not contain specific requirements on the largest amplitude that they should be executed (Krawinkler 2009). Thus, asymmetric and/or monotonic tests are deemed to be more appropriate for a component's seismic demand quantification prior to collapse (FEMA 2009b; Krawinkler 2009; Suzuki and Lignos 2015; Maison and Speicher 2016).

While asymmetric loading protocols have been established (Krawinkler et al. 2000a; b), they address specific needs related to near-fault ground motions with forward directivity. Whereas, they are also expressed as a function of a single deformation-controlled parameter. This is not suffice for steel MRF end columns experiencing transient axial load demands due to dynamic overturning effects. Therefore, dual-parameter loading protocols should be developed that couple the story drift loading reversals with the axial load variation. A compelling issue, which has been overlooked in past studies (Newell and Uang 2008), is how to consider the column axial load redistributions due to cyclic deterioration in the flexural strength of the respective steel beam intersecting a column's top end within a steel MRF.

This paper proposes dual-parameter collapse-consistent loading protocols for experimental testing of steel columns. Their primary instability mode is inelastic local buckling. The proposed protocols are based on concepts of cumulative damage and a statistical evaluation of seismic demands by means of nonlinear response history analyses through collapse. These analyses are performed to steel MRF building archetypes designed in highly seismic regions. The proposed loading protocols take into account relevant seismic capacity parameters (e.g., building height, the column local slenderness) as well as seismic demands imposed by ground motions with different characteristics. The effectiveness of the proposed loading protocols for highlighting the deterioration characteristics of steel columns is demonstrated with experimental data from a full-scale shake table collapse test of a 4-story steel building.

\section{GROUND MOTION SELECTION}

In order to develop realistic loading protocols for deterioration modeling of steel columns, two ground motion sets of large-magnitude, $M_{w}$ (i.e., $6.5 \leq M_{w} \leq 9$ ), which are recorded on soil types $\mathrm{C}$ and $\mathrm{D}$ are assembled. The first one represents ground motions with "near-fault" characteristics (herein is referred as "near-fault" set). The second set consists of long-duration records (referred as "long-duration" set). The sets are assembled from the NGA database (Chiou et al. 2008) and from the Center for Engineering Strong Motion Data database (CESMD 2012). Suzuki (2019) discusses how the selected records were filtered and base-line corrected.

In brief, the near-fault set was selected from records that their distance from the rupture zone ranges from 2.1 to $15 \mathrm{~km}$. Prior studies (Alavi and Krawinkler 2004) underscored the importance of the $T_{1} / T_{p}$ ratio ( $T_{1}$ : building's fundamental period) on the seismic demands of steel MRFs. The pulse period, $T_{p}$ of the most energetic pulse of the selected nearsource records, which was computed by Equation (1) (Alavi and Krawinkler 2004), is assumed to be strongly correlated with the moment magnitude, $M_{w}$ of the seismic event (Mavroeidis and Papageorgiou 2003; Alavi and Krawinkler 2004).

$\log _{10} T_{p}=-1.76+0.31 M_{w}$

In the context of the present study, $T_{1} / T_{p} \leq 1.0$ in all cases. Hence, the dynamic shear force distributions along the height of these buildings are relatively smooth. As such the maximum story drift angle demands should be expected in the bottom stories, regardless of the respective building strength (Alavi and Krawinkler 2004). The long-duration set is selected from earthquake records that have a significant duration (Trifunac and Brady 1975) larger or equal than 50 seconds. Their distance from the rupture zone ranges from 22 to $270 \mathrm{~km}$.

The record selection for the two sets is based on the conditional mean spectrum (CMS) (Baker 2011). The CMS is developed based on a target period, $T^{*}=1 \mathrm{sec}$ and the mean $+2 \sigma$ of the corresponding ground motion set. The selected period range was set to be from $0.2 T_{1}$ to $3.5 T_{1}$. Due to ground motion filtering, the reliability of the selected ground motion records is not guaranteed for periods larger than 4 seconds; therefore, an upper limit of 4 seconds was also imposed. Figure 1 illustrates the selected ground motion sets and corresponding CMS. 




(a) Near-fault ground motion set

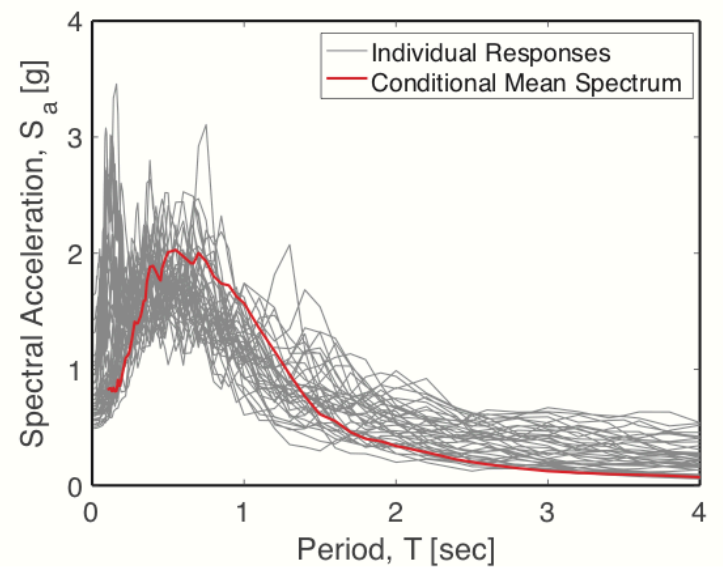

(b) Long-duration ground motion set

Figure 1. Absolute acceleration response spectra of selected ground motions for collapse-consistent loading protocol development.

\section{ARCHETYPE STEEL MOMENT RESISTING FRAMES FOR LOADING PROTOCOL DEVELOPMENT}

A survey of more than 40 building configurations of low- to mid-rise steel frame buildings (i.e., range of stories up to 12-stories) was conducted (Inoue et al. 1995; Hasegawa et al. 1998; Gupta and Krawinkler 2000a; NIST 2009; Elkady and Lignos 2014, 2015b) to develop archetype steel MRFs that encompass the common seismic design practice in highly seismic regions (AISC 2010; BCJ 2011). In brief, in buildings with 10-stories or less, 1- to 5-bays is common; whereas in buildings with more than 10-stories, 1- to 3-bays are typical. Figures $2 \mathrm{a}$ and $2 \mathrm{~b}$ show the typical story height-to-beam span width ratio, $H / L$, for end and interior columns based on the same survey. While a typical story height is 4 meters (i.e., 13ft), first story columns are typically up to 5 meters long (i.e., 15ft). For exterior bays, the $H / L$ ratio ranges from 0.33 to 1.0 ; for interior bays, it is common that $0.44 \leq H / L \leq 1.0$.

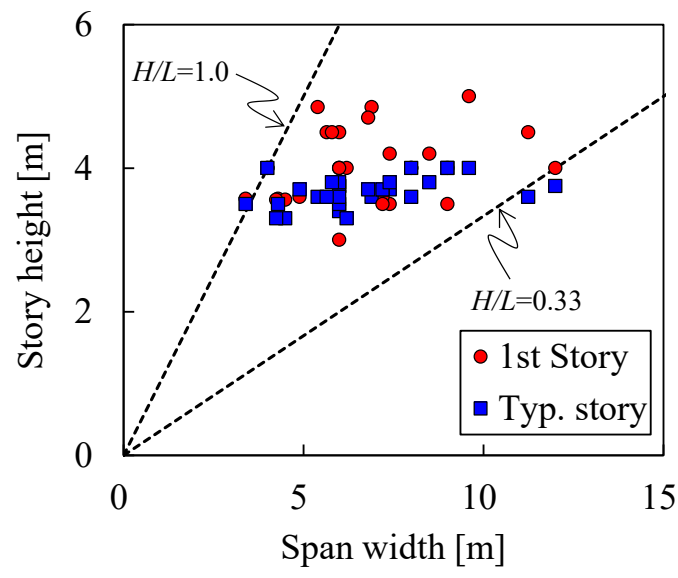

(a) End column

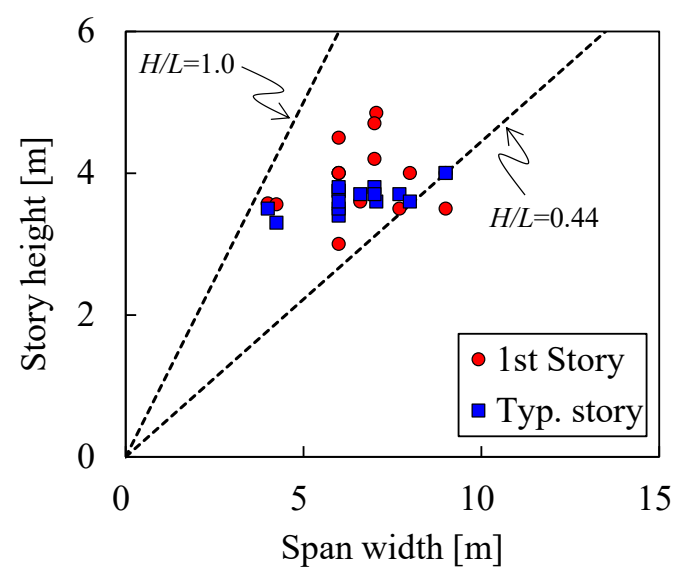

(b) Interior column

Figure 2. Story height versus span width for interior and end columns based on comprehensive survey.

A set of 82 archetypes comprising one, three- and four-bay steel MRF buildings was designed vis-à-vis the above discussion including cases with uneven bay lengths. The cross sections of the baseline archetypes satisfy the requirements for highly ductile members. The corresponding base shear coefficients, $n_{y}=V_{y} / W$ ( $W$ is the seismic weight) range from 0.08 to 0.80 . The predominant periods $T_{1}$ of the archetypes range from 0.50 to $3.50 \mathrm{sec}$ based on conventional eigenvalue analysis. Steel MRFs designed with North American provisions have lower base shear coefficients than steel MRFs designed with the Japanese provisions due to the strict drift limits imposed by the later 
for seismic events with a 50-year return period (Nakashima et al. 2000). Representative variations of critical steel MRF design requirements are also considered to examine their impact on the developed loading protocols. These include the employed strong-column-weak-beam (SCWB) ratio $(1.0,1.5$ and 2.0) as well as the steel column local web slenderness (wide flange cross sections, $16 \leq h / t_{w} \leq 55$, hollow structural sections (HSS), $15 \leq D / t \leq 40$ ).

\section{NONLINEAR BUILDING MODELS AND COLLAPSE SIMULATIONS}

The archetype steel MRFs are modeled in the Open System for Earthquake Engineering Simulation (OpenSees) platform (Mckenna 1997). Steel beams and columns are idealized with elastic beam-column elements with concentrated plasticity springs at their ends. Such springs feature the modified Ibarra-Medina-Krawinkler (IMK) deterioration model (Ibarra et al. 2005; Lignos and Krawinkler 2011). The deterioration parameters of HSS and wide flange cross-sections are computed based on multivariate regression expressions proposed in prior studies (Lignos and Krawinkler 2010, 2011; Hartloper and Lignos 2017). The panel zone shear distortion is modeled with the Krawinkler model (Gupta and Krawinkler 2000b). Column bases are idealized as fixed; hence the column-footing interaction is neglected (Zareian and Kanvinde 2013; Inamasu et al. 2019). Viscous damping is approximated with the Rayleigh model. Two percent damping ratio is assumed at $T_{1}$ and at $0.25 T_{1}$ of each steel MRF in accordance with (PEER/ATC 2010).

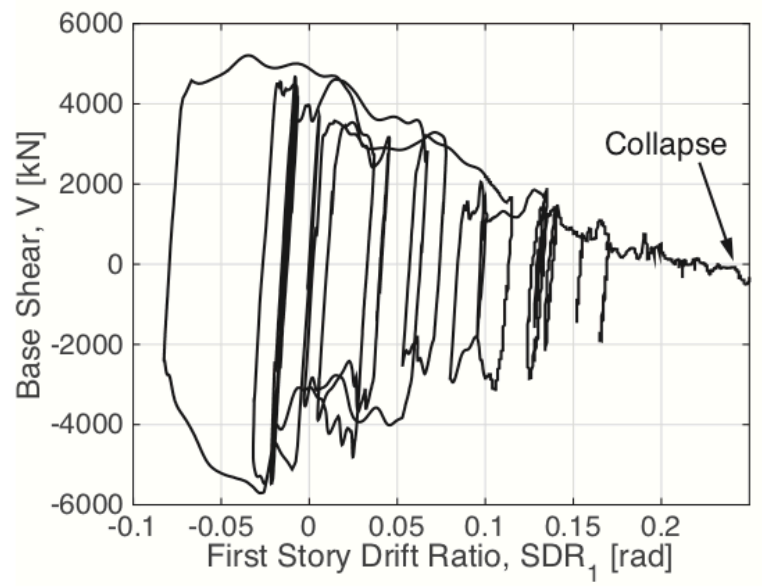

(a) Definition of sidesway instability (Collapse)

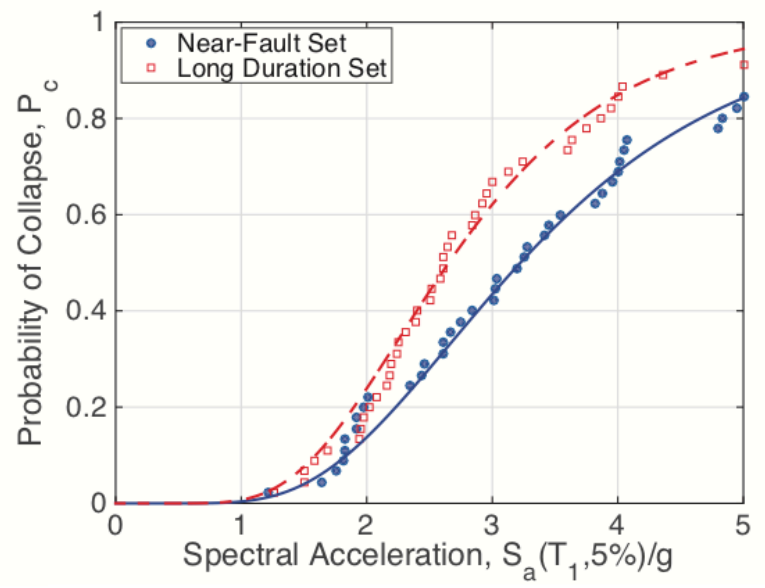

(b) Collapse fragility curves (8-story steel MRF)

Figure 3. Definition of dynamic instability and collapse fragility curves (8-story steel MRF).

The steel MRF numerical model representations are subjected to the ground motion sets discussed in Section 2. Incremental dynamic analysis (IDA) is conducted (Vamvatsikos and Cornell 2002) to trace dynamic collapse. The first mode spectral acceleration, $S_{a}\left(T_{1}\right) / g$ is used as the intensity measure for this purpose. Referring to Figure $3 \mathrm{a}$, collapse occurs once a steel MRF story (or a number of stories) deforms laterally so as the first order story shear resistance becomes zero due to P-Delta effects accelerated by component deterioration in strength and stiffness. This definition is consistent with prior observations from shake-table collapse experiments (Lignos et al. 2011, 2013). Figure $3 b$ illustrates for reference the collapse fragility curves of an 8-story steel MRF for the examined ground motion sets. When the long duration set is employed, the median collapse capacity of this MRF is about $20 \%$ smaller than that based on the near-fault set.

\section{DEFINITION OF SEISMIC DEMAND PARAMETERS FOR FIRST-STORY COLUMNS}

The premise of this paper is to fully define dual-parameter loading protocols to facilitate deterioration modeling of steel columns. Several column seismic demand parameters are extracted for this purpose. Due to their inherent lateral flexibility, steel MRFs may collapse due to P-Delta effects (Adam and Jäger 2012). However, the load carrying capacity of the first-story steel MRF columns may still be considerable. Therefore, extracting the column seismic demand parameters at the median collapse intensity is not sufficient. Instead, the $10 \%$ percentile values are selected for this purpose; thus, mean-effects shall be expected. 
In the subsequent discussion, a loading cycle is defined as a closed unit with equal deformation ranges in both loading directions (Krawinkler et al. 2000a). A loading cycle may have a mean deformation. A single excursion causes damage primarily in one loading direction. It is assumed that a ground motion response history is assembled by response excursions following a pattern controlled by the ground motion and building characteristics. In steel columns, the yield rotation, $\theta_{y}$ depends on the applied axial load ratio, $P / P_{y}$, and the moment gradient during the response history; thus, the column plastic rotation, $\theta_{p l}$, is selected herein as a basic seismic demand quantity for the lateral loading protocol development.

The definitions of a column's seismic demand parameters are extracted from individual column moment-rotation relations similar to the one shown in Figure 4a. The column end moment is normalized with respect to the crosssection's plastic flexural resistance, $M_{p l}=Z \cdot f_{y}\left(Z\right.$ is the section plastic modulus; $f_{y}$ is the expected yield stress of the steel material).

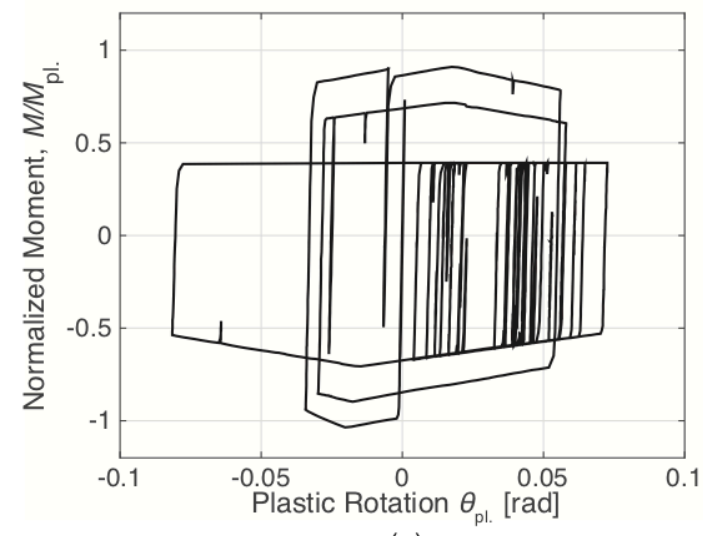

(a)

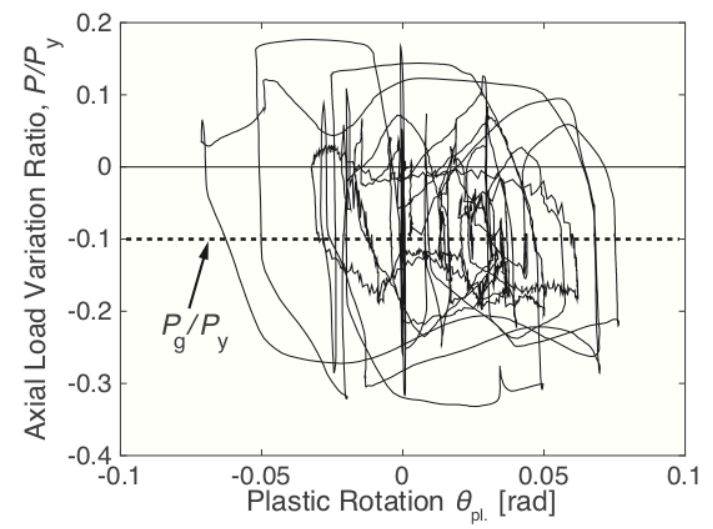

(c)

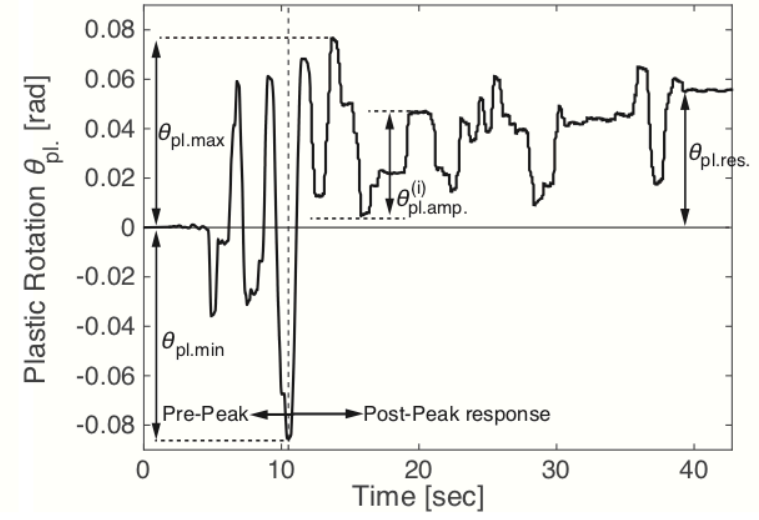

(b)

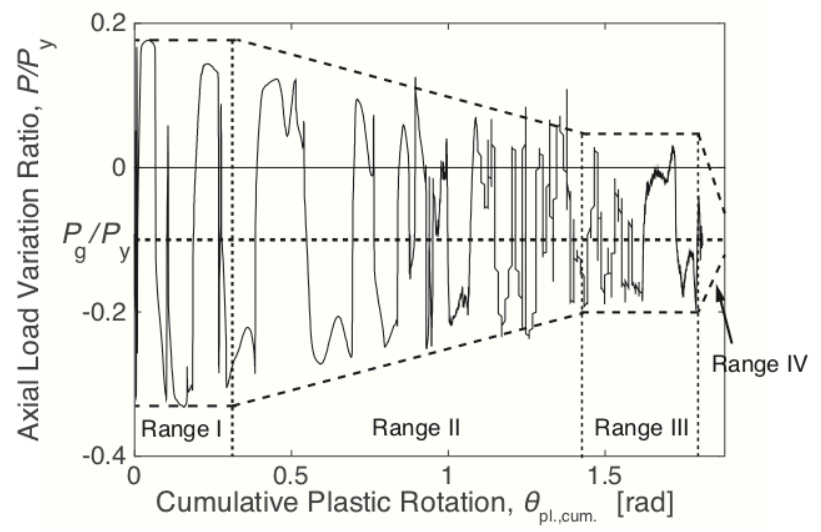

(d)

Figure 4. Definition of seismic demand parameters for loading protocol development - Baseline archetype: 8story, 4-bay steel moment resisting frame.

The seismic demand parameters of interest in terms of column response deformation are defined in Figure $4 \mathrm{~b}$ and include: (a) the maximum, $\theta_{p l, \text { max }}$, and minimum, $\theta_{p l, \text { min }}$, plastic rotations, experienced during the seismic response that define the maximum plastic deformation range, $\Delta \theta_{p l, \text { max }}$; (b) the maximum plastic rotation amplitude, $\theta_{\text {pl,amp. }}^{i}$, at a given loading excursion, $i$, and the global maximum, $\theta_{p l, \text {,amp. }}$; (c) the cumulative plastic rotation, $\sum \theta_{p l .}^{i}$; (d) the mean (i.e., residual) plastic rotation, $\theta_{\text {pl.,res. }}$; and (e) the number of inelastic cycles, $N_{p}$ (i.e., cycles with amplitude larger than the column's yield rotation, $\theta_{y}$ ), experienced during the pre- and post-peak seismic response (see Figure $4 \mathrm{~b}$ ). The model employed for cumulative damage assessment is based on the two hypotheses of a Manson-Coffin relationship (Coffin 1954; Manson 1954) and Miner's rule (Miner 1945). The cumulative damage model is applied up 
to the peak response (i.e., $\theta_{p l, a m p .}$ ) to track the cumulative damage prior to the main inelastic deformation amplitude. The same model is also applied separately in the post-peak response to track sequence effects. The mean plastic rotation, $\theta_{\text {pl.res. }}$ is tracked at the end of each ground motion record. Inelastic cycles with an amplitude range smaller than 0.02rads are disregarded. These cycles have a negligible effect on the column response at large deformations (Krawinkler et al. 1983; Krawinkler 1996).

Figure $4 \mathrm{c}$ shows the axial load ratio variation, $P / P_{y}$ ( $P$ : corresponding axial load demand; $P_{y}$ is a steel column's axial yield strength) versus the plastic rotation, $\theta_{p l}$, relation of an end column within an 8-story steel MRF. This frame is subjected to the East West component of the Hachinohe seismic record from the 1968 Tokachi-oki earthquake. This relationship is characterized by three distinct ranges that can be clearly seen if $P / P_{y}$ is plotted with respect to the cumulative plastic rotation, $\theta_{\text {pl.,cum. }}$ (see Figure $4 \mathrm{~d}$ ):

- Range I: local buckling has not occurred, and the column's response is dominated by cyclic hardening,

- Range II: axial strength deterioration proceeds at a high rate, which is associated with the continuous growth of local buckling of the column,

- Range III: deterioration proceeds at a fairly constant rate due to the local buckle size stabilization for steel columns under modest axial load demands (i.e., $P / P_{y} \leq 0.30$ ).

Steel column experiments (Suzuki and Lignos 2015; Elkady and Lignos 2018a) suggest that there is a fourth range (Range IV) in which a column loses its axial load carrying capacity due to the rapid progression of axial shortening. The four ranges are analogous with those observed in steel beams (Krawinkler et al. 1983). However, in Range IV the latter experience ductile tearing instead of axial shortening. Referring to Figure $4 \mathrm{~d}$, it was found statistically that in Range I, the axial load variation is fairly stable up to about $1.5 \theta_{p}\left(\theta_{p}\right.$ column's pre-peak plastic rotation capacity) regardless of the employed ground motion set. In Range II, the axial load variation amplitude decays with a rate (i.e., slope) corresponding to that of the post-peak plastic rotation, $\theta_{p c}$ of the steel column; finally, the axial load variation amplitude attains a stable path (i.e., Range III) with an amplitude of $0.4 P / P_{y}$ prior to the loss of the axial load carrying capacity of the column (i.e., Range IV).

\section{STATISTICAL TRENDS OF SEISMIC DEMAND PARAMETERS}

This section illustrates the statistical trends that highlight the dependence of a steel column's seismic demands on key structural parameters as well as ground motion aspects. The discussion is based on a statistical evaluation of the demand data directly extracted from collapse simulations outlined in Section 3. Figures 5 and 6 show the median values of a column's seismic demand parameters with the same local slenderness ratio, $D / t$ and building archetypes with the same number of bays. Due to brevity, the discussion is only limited to seismic demand parameters that are crucial to construct a collapse-consistent loading protocol. The straight lines in some of these figures are only used to demonstrate trends between seismic demand and structural parameters. The discussion below is based on results from HSS columns but the findings are later on generalized for wide-flange steel columns based on additional collapse simulations that were conducted with archetypes comprising steel MRFs with wide-flange steel columns (NIST 2009; Elkady and Lignos 2014, 2015b). The reported statistics for wide-flange steel MRF columns have been reported in prior work by the second author (Elkady and Lignos 2017).

\section{Dependence on building height}

Figures $5 \mathrm{a}$ and $5 \mathrm{~b}$ show that an increase in the building height is associated with a decrease in the seismic demand parameters regardless of the employed ground motion set. This is due to the fact that mid- to high-rise steel MRFs are susceptible to P-Delta effects due to their inherent flexibility (Adam and Jäger 2012). Referring to Figure 5a, the column's median plastic rotation amplitude, $\theta_{p l, a m p}$. demands is somewhat dependent with regards to the employed ground motion set prior to structural collapse. On the other hand, the median column cumulative plastic rotation demands, $\sum \theta_{p l}^{i}$. in low-rise steel MRF buildings under long-duration records are, on average, three to six times larger than those expected in near-fault ground motions (see Figure 5b). This is due to the large number of inelastic deformation cycles contained within a long-duration record. The observed variability is due to the steel column's local slenderness as well as the lower base shear coefficients that archetypes with the same height may have due to the bay number variation. Interestingly, such differences practically diminish for long-period buildings (i.e., increase of 
height) since they only experience few large inelastic cycles. This may not hold true for long-duration ground motions recorded on soft soils. Large amplitude inelastic cycles may be expected in this case depending on the building-to-soil period ratios (Krawinkler 2009). This is outside the scope of the present paper.

\subsection{Dependence on local slenderness ratio}

Figure $5 \mathrm{~b}$ suggests that slender columns $(D / t \geq 28)$ experience fairly large cumulative plastic rotation demands. This is due to the early occurrence of yielding and local buckling; hence, the influence of small inelastic excursions on the overall column performance is more pronounced prior to collapse (Krawinkler 1996). Interestingly, apart from very slender cross-sections, the observed differences diminish while the number of stories increase. The reason is that taller steel MRF buildings are typically designed with very compact column cross-sections $(D / t<22)$; hence the destabilizing effects of gravity load dominate the steel MRF behavior (Adam and Jäger 2012).

Figure $5 \mathrm{c}$ depicts the dependence of the mean peak plastic rotation demands on $D / t$. These figures suggest that seismically compact steel columns in accordance with current seismic provisions (Architectural Institute of Japan 1996; AISC 2010; BCJ 2011) tend to reach an average of 4-6\% plastic rotation amplitude prior to collapse regardless of $D / t$. Although stocky columns would be subjected to a large plastic deformation amplitude prior to collapse, Figure 6c suggests the opposite. Tall steel MRF designs typically employ highly compact columns; hence, P-Delta effects govern dynamic collapse as discussed earlier.

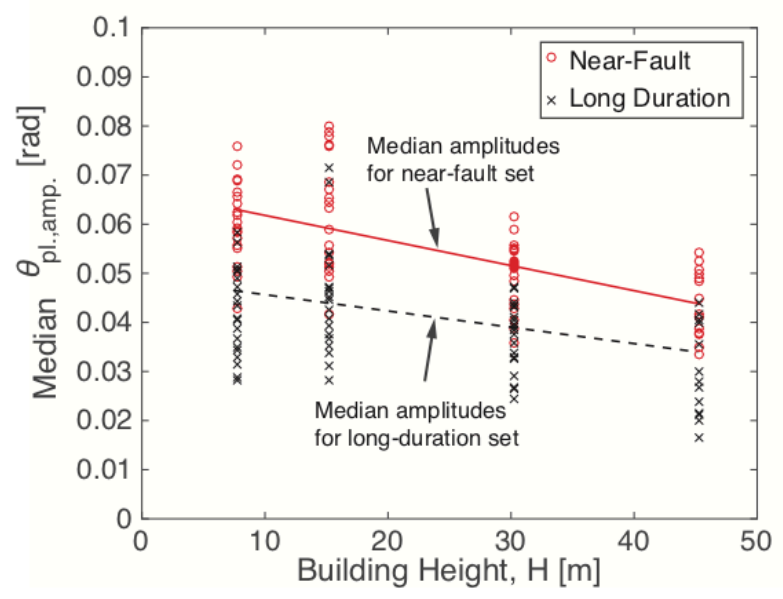

(a)

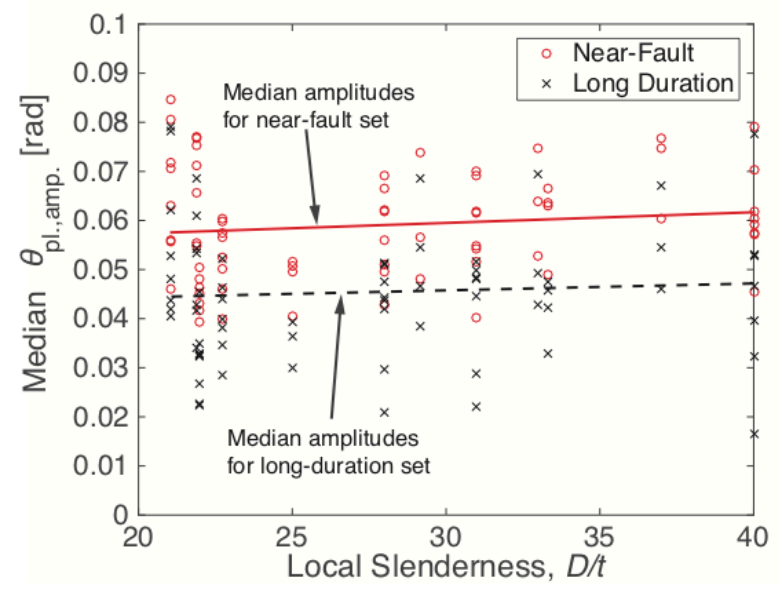

(c)

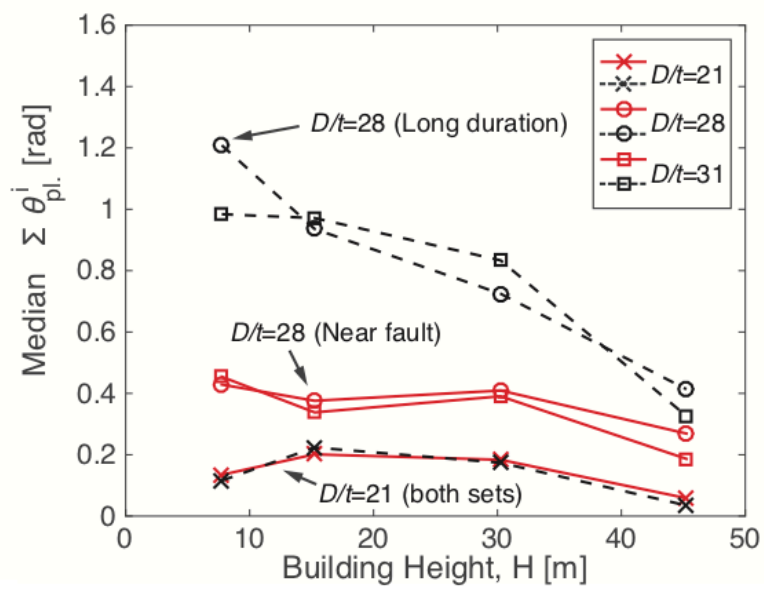

(b)

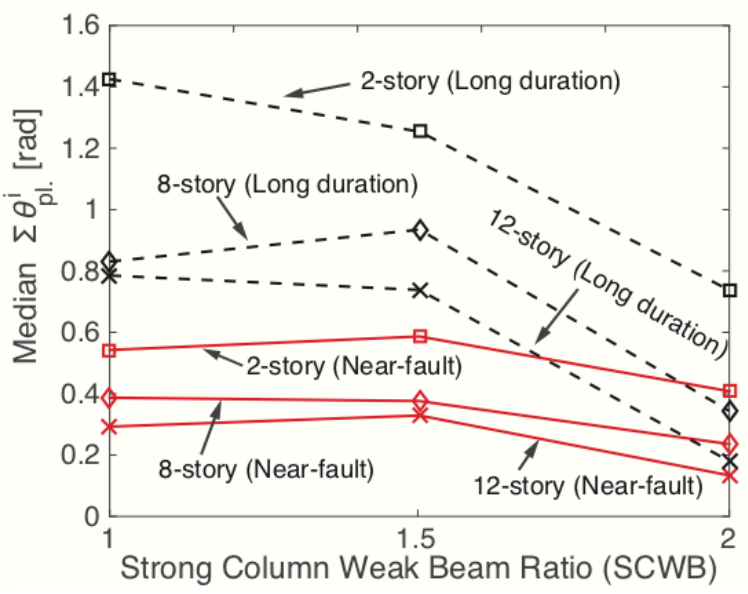

(d)

Figure 5. Dependence of median seismic demand parameters of first-story steel MRF columns on building geometry, cross-section slenderness, strong column/weak beam ratio and ground motion type. 


\section{Dependence on strong-column-weak-beam ratio}

This capacity design requirement is found to somewhat affect the steel MRF column behavior. For SCWB $\geq 2.0$, a typical beam collapse mechanism is likely to form (Elkady and Lignos 2014, 2015b); hence, first-story columns remain elastic even at large lateral drift demands. As such, the ground motion type has a negligible effect on the median $\sum \theta_{p l .}^{i}$. (i.e., $\sum \theta_{p l \text {. }}^{i}<0.8 \mathrm{rad}$ ) as depicted in Figure $5 \mathrm{~d}$. This is inherently captured in the dependency of $\sum \theta_{p l .}^{i}$ on $D / t$. A more compact column would imply a higher SCWB ratio for a given steel MRF beam size, thereby pronouncing its cumulative plastic deformation demands. Local story collapse mechanisms are likely to form when smaller SCWB ratios (i.e., SCWB > 1.0) are employed (Gupta and Krawinkler 2000b; Elkady and Lignos 2014).

\section{Mean and sequence effects}

Code-conforming buildings subjected to a low probability of occurrence seismic event are likely to experience large mean deformations (Ramirez and Miranda 2012; Hwang and Lignos 2017). These buildings oscillate around a mean deformation after experiencing a large loading excursion (i.e., peak-response). Depending on the ground motion type, the loading cycles prior and subsequent to the column's peak-response may cause strength and stiffness deterioration under cyclic loading. Figure 6 shows representative comparisons of median cycle amplitudes and means normalized with respect to the maximum cycle amplitude for the near fault set. From this figure, it is evident that the median normalized means nearly overlap with the median normalized loading cycle amplitudes. Therefore, mean effects are significant regardless of the ground motion set. This is to be expected for low-probability of occurrence seismic events due to ratcheting (Ibarra and Krawinkler 2005). Same observations hold true for the long-duration set but are not shown here due to brevity.

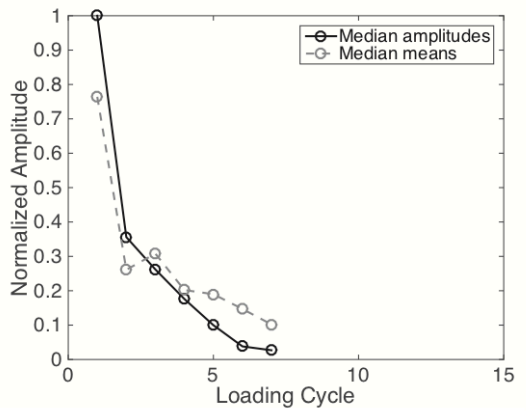

(a) 2-story

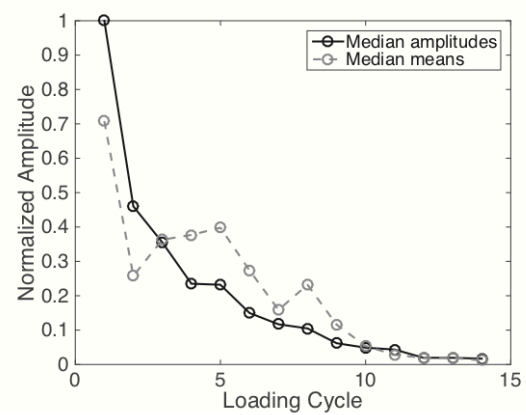

(b) 4-story

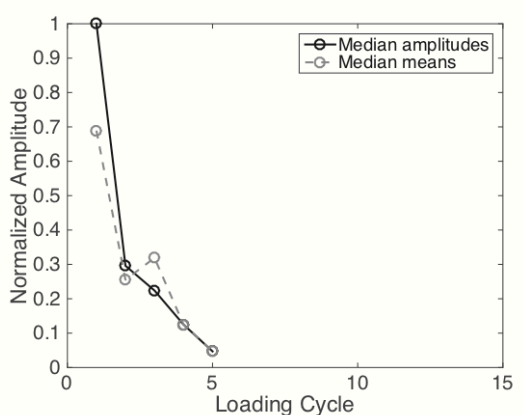

(c) 8-story

Figure 6. Comparison of normalized median cycle amplitudes and normalized median cycle means for selected steel MRF systems (near-fault set).

Figure 7 depicts the median normalized mean plastic rotation, $\theta_{p l ., \text { res. }}$ with respect to the steel MRF height for the two ground motion sets. The general trend is that a column's residual plastic deformation in the post-peak response is marginally larger in low-rise steel MRF buildings than those observed in mid- to high-rise buildings. Flexible steel MRF buildings are more likely to collapse than to experience residual deformations due to their sensitivity to P-Delta effects. Interestingly, the first story steel MRF column mean $\theta_{p l, \text {,res. }}$ demands under the long duration set (see Figure $7 b$ ) are, on average, about $1 / 3$ smaller than those seen under the near-fault set (see Figure 7a). This is in part attributed to the long-period pulse, $T_{p}$ of near-fault ground motions that impose structures into large lateral drift demands. Moreover, structures in the short period spectral region tend to develop large residual deformations compared to longer period structures (Krawinkler et al. 2000a; Alavi and Krawinkler 2004).

Sequence effects are typically not addressed in current incremental loading protocols for experimental testing of structural components (Krawinkler et al. 2000a). Figure 8 illustrates the median number of inelastic cycles $N_{p}$ in the inelastic cyclic range of $0-0.02$ rads for the two ground motion sets considered in the pre- and post-peak column response. Referring to Figure 8a, first-story columns in short-period steel MRFs subjected to long-duration records experience five times more inelastic loading cycles than those subjected to the near-fault set prior to the peak response. These differences become less pronounced while the building height increases. Although the general trend in the post- 
peak response range is the same, the ratio between $N_{p}$ of long duration-to-near fault records is, on average, 3:1 in the short period range.

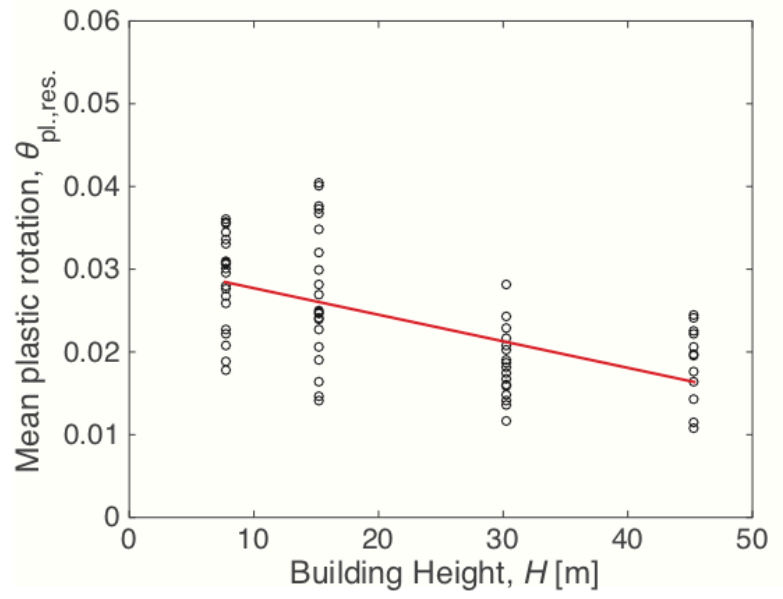

(a) Near-fault set

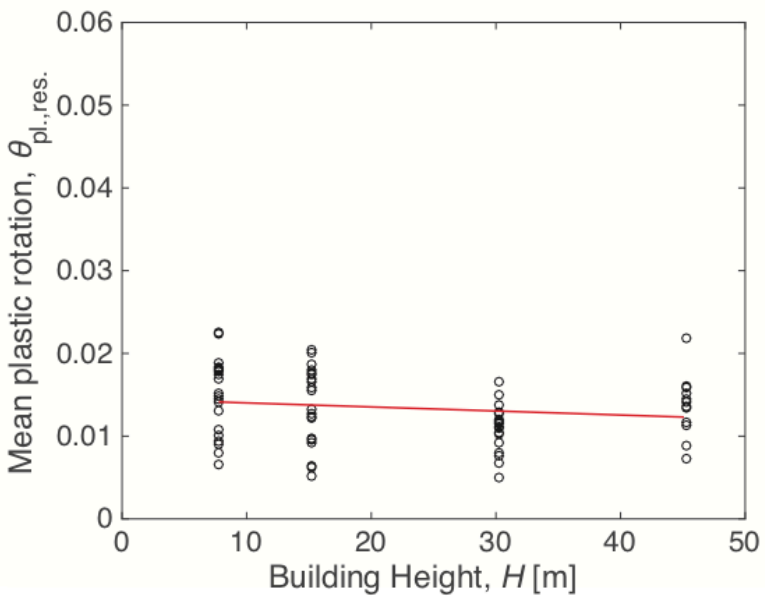

(b) Long duration set

Figure 7. Dependence of median mean plastic rotation, $\theta_{p l, \text { res. }}$ demands of first story steel columns on building height, $\boldsymbol{H}$.

Sequence effects are important for deterioration modeling of steel columns since these may experience considerable axial shortening (Suzuki and Lignos 2015; Ozkula et al. 2017; Elkady and Lignos 2018a). This depends on both the number and sequence of inelastic loading excursions (Elkady and Lignos 2018b). Small inelastic deformation excursion ranges observed in the examined long-duration set are not expected to cause considerable cyclic strength deterioration. However, the large number of cycles may cause ultra-low cycle fatigue (Okazaki et al. 2013). These observations are important from a repairability standpoint.

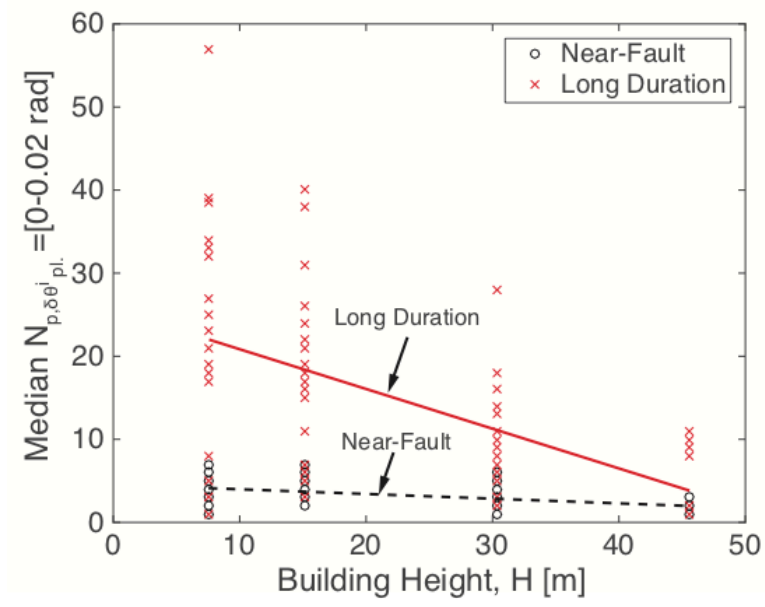

(a)

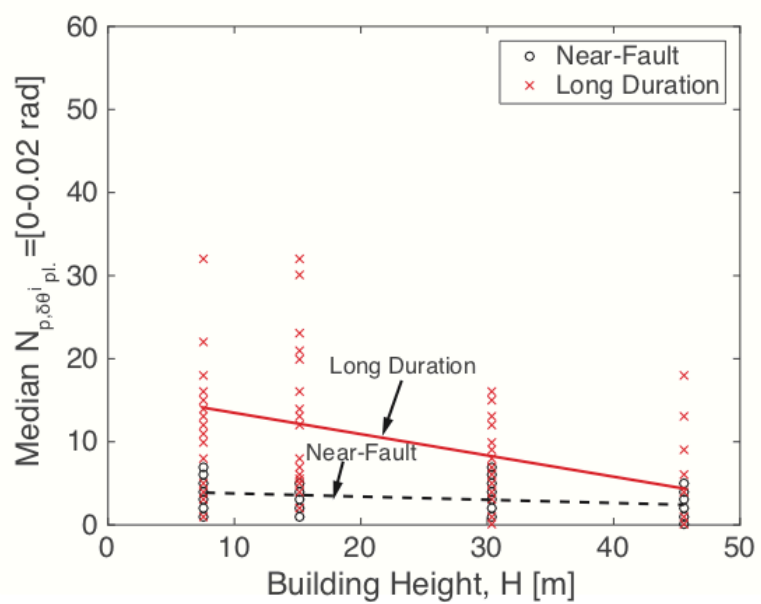

(b)

Figure 8. Dependence of loading cycles, $N_{p}$ within $\delta \theta_{p l .}=0-0.02$ rads on building height, $H$; (a) pre-peak response range; (b) post-peak response range.

\section{Axial Load Variation}

Figure 9 illustrates the end column axial load ratio variation amplitude range in tension, $P_{t} / P_{y}$, and compression, 
$P_{c} / P_{y}$, versus the building height, $H$, conditioned on the number of steel MRF bays. The gravity-induced axial load ratio, $P_{g} / P_{y}$, is also superimposed in the same figure. Unlike interior columns, an increase in the steel frame building height is associated with a clear increase of the end column's axial load variation amplitude regardless of the number of MRF bays. Figure 9 suggests that a very practical approach can be employed to estimate the axial load variation amplitude in end columns. In particular, Eq. (2) may be utilized for this purpose,

$P_{1}=P_{g, 1}+P_{H, 1}=\frac{w \cdot l \cdot N}{2}+\frac{n_{y} \cdot w \cdot h \cdot N}{2} \cdot \sum_{j=1}^{N}\left(\sqrt{1-\frac{j-1}{N}}+\sqrt{1-\frac{j}{N}}\right)$

in which, $P_{1}$ is the axial load of a first story end column under gravity-induced axial load, $P_{g, 1}$, and axial load, $P_{H, 1}$ due to the lateral loading; $w$ is the unit gravity load on a beam member; $l$ is the respective beam span; $N$ is the number of stories; $n_{y}$ is the base shear coefficient of the steel MRF; and $h$ is the corresponding story height. This equation is in agreement with similar expressions presented in Inoue et al. (1995). Alternatively, a nonlinear static analysis based on a first-mode lateral load pattern suffice to trace the axial load variation amplitude in first story steel MRF end columns (Lignos et al. 2015).

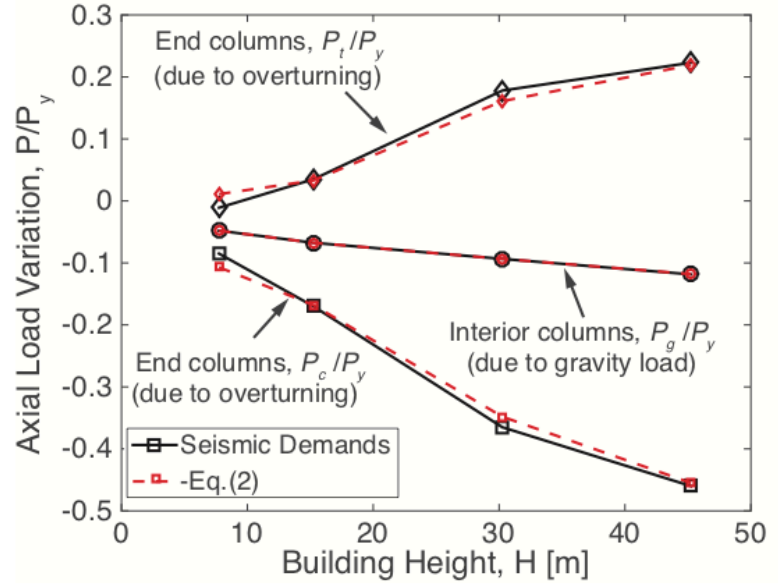

(a) Steel MRFs with 4-bays

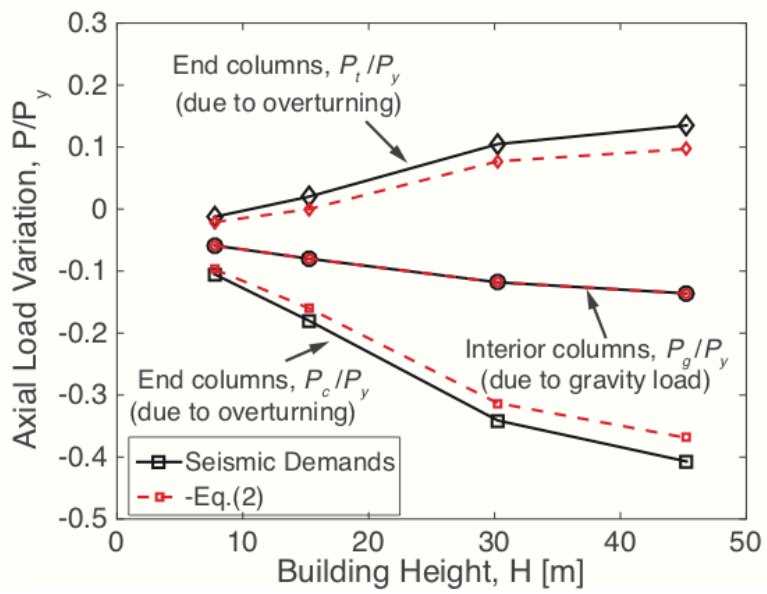

(b) Steel MRFs with 3-bays

Figure 9. Dependence of first story end column axial load variation amplitude with respect to the building height and number of bays.

\section{LOADING PROTOCOL DEVELOPMENT FOR DETERIORATION MODELING OF STEEL COLUMNS}

The general methodology for the development of collapse-consistent protocols for experimental testing of steel columns is based on cumulative damage concepts discussed in (Krawinkler et al. 1983). Although a steel MRF column is subjected to coupled variable axial force and lateral drift demands, it is assumed that the steel column damage potential due to local buckling-induced softening is primarily attributed to large inelastic deformation amplitudes. Thus, the contribution of elastic deformation to damage is considered negligible.

A challenge to be addressed first is to establish the relationship of the $P / P_{y}$ with respect to the column's plastic rotation demands, $\theta_{p l}$. Referring to Figure 10a, an empirical axial load-plastic rotation backbone curve is developed for columns experiencing local-buckling-induced softening. This relationship can be mathematically described as follows on the basis of statistical trends discussed in Section 6.5, 
$\frac{P}{P_{y}}=\left\{\begin{array}{l}P_{g} / P_{y}, \quad \theta_{p l .}=0 \\ P_{\max } / P_{y}, \quad 0<\theta_{p l .} \leq \theta_{p} \\ P_{\max } / P_{y}, \quad \theta_{p}<\theta_{p l .} \leq 1.5 \cdot \theta_{p} \\ \left(1+1.5 \cdot \theta_{p} / \theta_{p c}-\theta_{p l .} / \theta_{p c}\right) \cdot P_{\max } / P_{y}, 1.5 \cdot \theta_{p}<\theta_{p l .} \leq 1.5 \cdot \theta_{p}+0.6 \cdot \theta_{p c} \\ 0.4 \cdot P_{\max } / P_{y}, \quad \theta_{p l .}>1.5 \cdot \theta_{p}+0.6 \cdot \theta_{p c}\end{array}\right.$

In which, $P_{\max } / P_{y}$ is the expected column axial load ratio variation amplitude (see Figure 9). The pre- and post-peak plastic rotations, $\theta_{p}$ and $\theta_{p c}$, respectively, are shown in Figure 10b. These should be computed after conducting a monotonic experiment in which a column should be subjected to the corresponding gravity-induced axial load demand, $P_{g} / P_{y}$ coupled with monotonically increasing lateral drift demands. The steel column shall be pushed to a lateral deformation associated with at least $50 \%$ loss of its first order peak flexural resistance, $M_{\max }$, as shown in Figure $10 \mathrm{~b}$. Alternatively, continuum finite element models based on the procedures proposed by Elkady and Lignos (2018b) may be used to estimate the $\theta_{p}$ and $\theta_{p c}$ values of a steel column. Empirical equations for HSS (Lignos and Krawinkler 2010) and wide flange columns (Lignos et al. 2019) are also available.

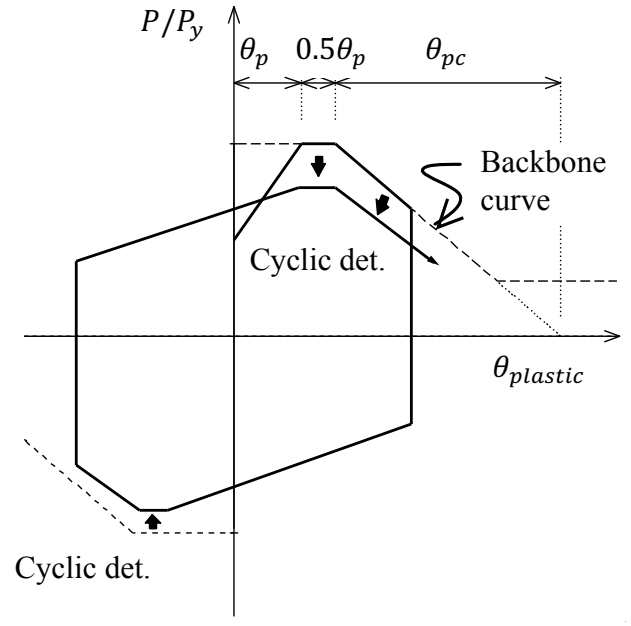

(a)

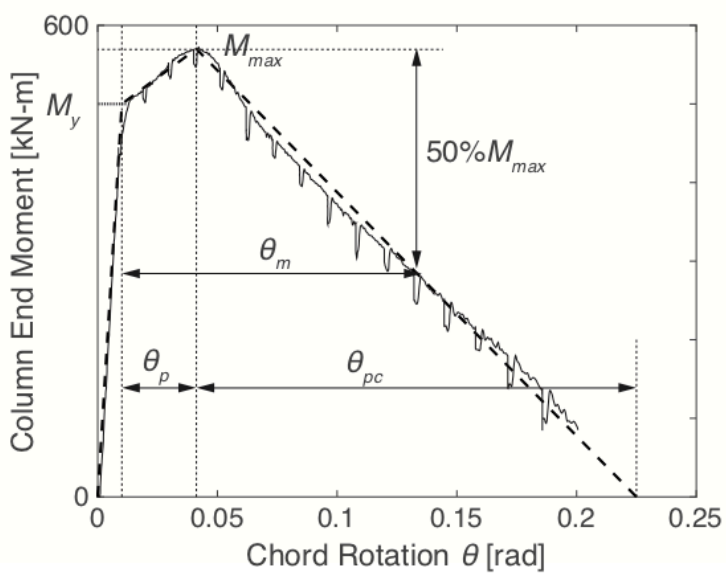

(b)

Figure 10. (a) Axial load - plastic rotation relation; (b) definition of column model parameters based on a standard monotonic test (test data from Suzuki and Lignos 2015).

Equation (3) defines the upper/lower bound of the column axial load variation demands for a given steel column lateral loading history, $\theta_{p l}(t)$ (e.g., see Figure $5 \mathrm{~b}$ ). Referring to Figs 11a and $11 \mathrm{~b}$, the expected axial load variation amplitude, $P_{\max , i}$ (noted as measurement), at a loading excursion, $i$, reduces while the cumulative plastic rotation, $\sum \theta_{p l .}^{i}$, of the column increases. This can be mathematically represented by the following empirical relationship,

$P_{\max , i}=P_{H, 1} \cdot\left(1-\frac{\sum \theta_{p l}^{i}}{1.2 \cdot \Lambda}\right)$

where, $\Lambda$ is the reference cumulative rotation capacity of a steel column (Ibarra et al. 2005; Lignos and Krawinkler 2011) and can be predicted by readily available empirical expressions for HSS (Lignos and Krawinkler 2010) and wide-flange columns (Lignos et al. 2019).

Figure 11 shows representative comparisons between the empirical formulation described by Equations (3) and (4) and actual column responses (termed as measurement) from nonlinear response history analyses. The comparisons suggest that the $P / P_{y}-\theta_{p l}$. synchronization is represented reasonably well regardless of the ground motion type and building typology. 


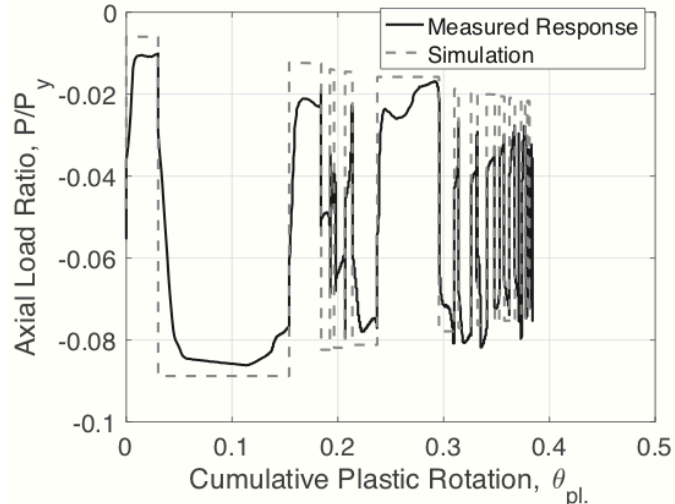

(a) 2-story steel MRF

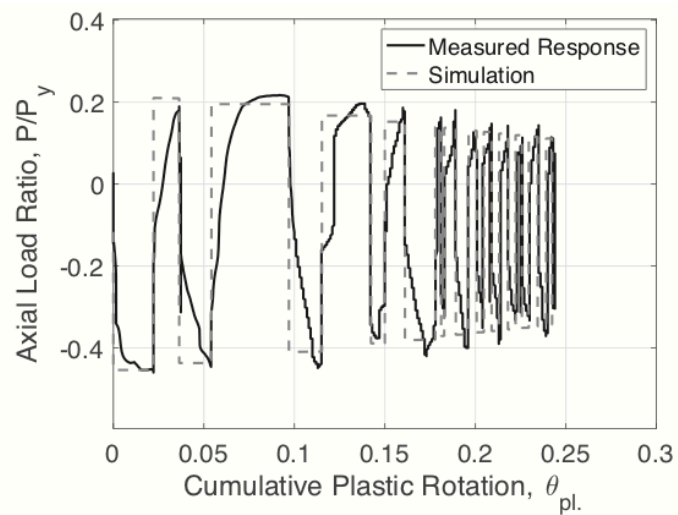

(b) 12-story steel MRF

Figure 11. Illustration of $P / P_{y}-\theta_{p l}$. synchronization for a steel column.

To fully describe the collapse-consistent protocol, the lateral loading indexes should be explicitly defined. Figure 12a shows the median value of the normalized plastic deformation amplitude, $\theta_{p l ., a m p}$. with respect to the building height for the evaluated ground motion sets. The peak response, $\theta_{p l, a m p}$. is normalized with respect to the ultimate rotation, $\theta_{m}$ of a column as defined in Figure 10b. The $\theta_{p l, a m p .} / \theta_{m}$ ratio is a fairly stable parameter regardless of the building height. Referring to Figure $12 \mathrm{~b}$, the dependence of the local slenderness on $\theta_{p l, a m p .} / \theta_{m}$ with respect to the steel column's local slenderness, $D / t$ is strongly linear. However, this effect is inherently captured in the $\theta_{p l, a m p .} / \theta_{m}-H$ relation shown in Figure 12a since taller buildings are designed with more compact column cross-sections compared to low-rise ones. Same observations hold true for the normalized mean effects (i.e., $\theta_{\text {pl.res. }} / \theta_{m}$ ).

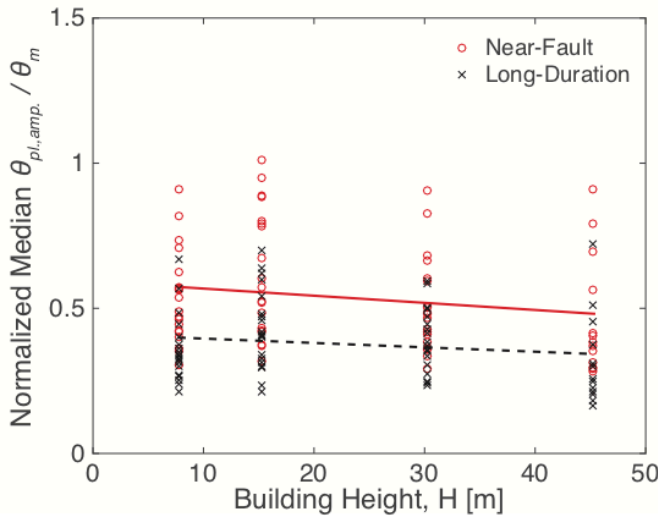

(a)



(c)

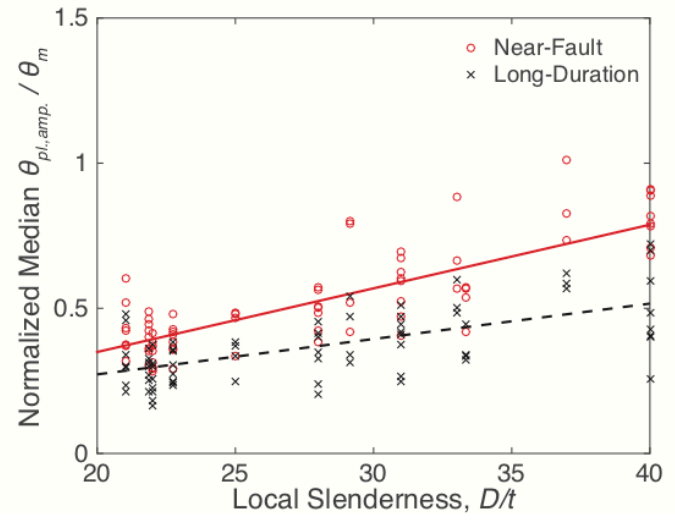

(b)

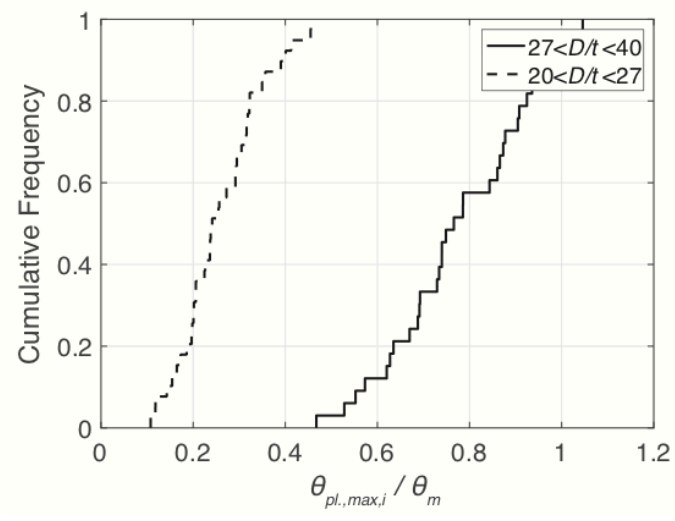

(d) 
Figure 12. Dependence of normalized median plastic rotation amplitude with respect to (a) building height; and (b) local slenderness for different ground motion sets; (c) cumulative frequency of normalized minimum amplitude for near-fault ground motions; and (d) cumulative frequency of normalized max amplitude for near-fault ground motions.

The $90^{\text {th }}$ percentile of the cumulative frequency distributions of the normalized loading protocol indexes are utilized in all cases to define the lateral loading protocol indexes based on the Krawinkler et al. (1983) methodology. Figures $12 \mathrm{c}$ and $12 \mathrm{~d}$ illustrate examples for $\theta_{\text {pl.min. }} / \theta_{m}$ and $\theta_{\text {pl.max. }} / \theta_{m}$, respectively, for two local slenderness ranges for the near-fault ground motion set. The selected $90 \%$ percentiles coincide with the values summarized in Table 1 for the normalized loading protocol indexes in terms of $\theta_{\text {pl.max. }}$ and $\theta_{\text {pl.min. }}$ as well as the residual plastic rotation.

The remaining two aspects to construct the loading protocol entail the number of primary cycles in the pre-peak response as well as the number of interruptions (i.e., trailing cycles) in the pre- and post-peak response. Figure 13a suggests that the total number of inelastic cycles (i.e., $\theta>\theta_{y}$ ) a column experiences under long duration records is, on average, 5 times more than those seen under near-fault records in the short period range. However, the number of primary inelastic cycles (i.e., the ones that widen the deformation amplitude) in both cases is not that different as shown in Figure 13b. In that respect, the only difference in inelastic cycle deformation demands between near-fault and long-duration records is the trailing cycles in-between primary loading cycles in the pre-peak response and those observed in the post-peak response. However, these cycles have a practically negligible effect on the collapse performance of a steel column (Krawinkler et al. 1983, 2000a; Krawinkler 1996). The number of interrupting inelastic cycles is arranged such that the unloading stiffness deterioration of a steel column can be reliably quantified at various loading stages (Elkady and Lignos 2018b).

Table 1. Normalized loading protocol index definitions depending on column local slenderness and column cross-section profile.

\begin{tabular}{|c|c|c|c|c|}
\hline $\begin{array}{c}\text { Ground Motion } \\
\text { Type }\end{array}$ & Cross-Section Slenderness & $\boldsymbol{\theta}_{p l, \text { max. }} / \boldsymbol{\theta}_{m}$ & $\boldsymbol{\theta}_{p l, \text { min. }} / \boldsymbol{\theta}_{m}$ & $\boldsymbol{\theta}_{\text {pl,res. }} / \boldsymbol{\theta}_{m}$ \\
\hline \multirow{2}{*}{ Near-Fault } & $\begin{array}{ll}\text { HSS } & 20 \leq D / t \leq 27 \\
\text { Wide flange } & 16 \leq h / t_{w} \leq 35\end{array}$ & 0.40 & -0.15 & 0.10 \\
\hline & $\begin{array}{ll}\text { HSS } & 27<D / t \leq 40 \\
\text { Wide flange } 35<h / t_{w} \leq 55\end{array}$ & 1.00 & -0.40 & 0.30 \\
\hline \multirow{2}{*}{ Long Duration } & $\begin{array}{lc}\text { HSS } & 20 \leq D / t \leq 27 \\
\text { Wide flange } & 16 \leq h / t_{w} \leq 35\end{array}$ & 0.30 & -0.08 & 0.08 \\
\hline & $\begin{array}{ll}\text { HSS } & 27<D / t \leq 40 \\
\text { Wide flange } & 35<h / t_{w} \leq 55\end{array}$ & 0.80 & -0.08 & 0.25 \\
\hline
\end{tabular}

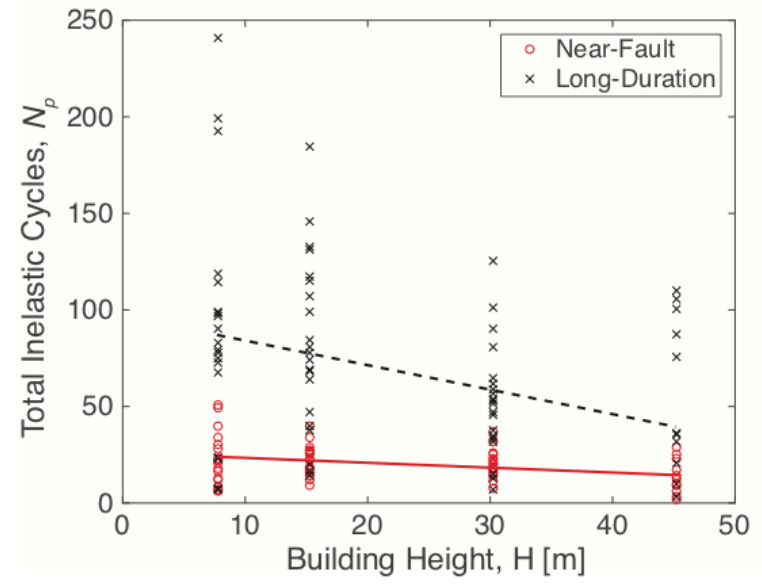

(a)

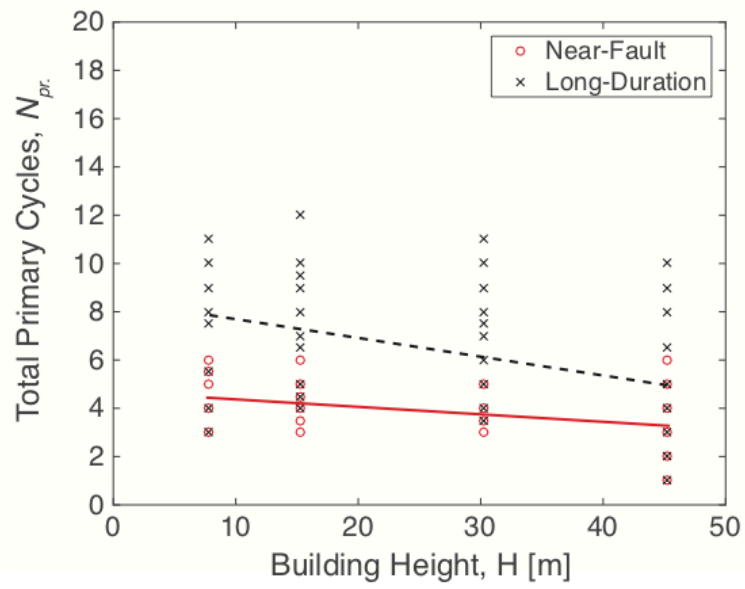

(b) 
Figure 13. Influence of building height on the total and primary number of inelastic cycles.

The corresponding lateral loading histories, which are also shown in Figure 14 have the following lateral loading cycle arrangement:

HSS: $20 \leq D / t \leq 27$, wide flange: $16 \leq h / t_{w} \leq 35$ :

Near-fault protocol (Figure 14a):

- There are two cycles with amplitude of $0.05 \theta_{m}$

- There are two cycles with amplitude of $0.15 \theta_{m}$

- There are three trailing cycles with amplitude $0.05 \theta_{m}$ following the primary cycle of amplitude $0.4 \theta_{m}$ with a mean normalized residual deformation of $0.08 \theta_{m}$.

Long-duration protocol (Figure 14b):

- There are two cycles with amplitude of $0.02 \theta_{m}$

- There are three cycles with amplitude of $0.05 \theta_{m}$

- There is one cycle with amplitude of $0.15 \theta_{m}$

- There are two trailing cycles with amplitude of $0.05 \theta_{m}$

- $\quad$ There is one cycle with amplitude of $0.15 \theta_{m}$

- There are three trailing cycles with amplitude $0.02 \theta_{m}$ and five trailing cycles with amplitude $0.05 \theta_{m}$ following the primary cycle of amplitude $0.3 \theta_{m}$ with a mean normalized residual deformation of $0.05 \theta_{m}$.

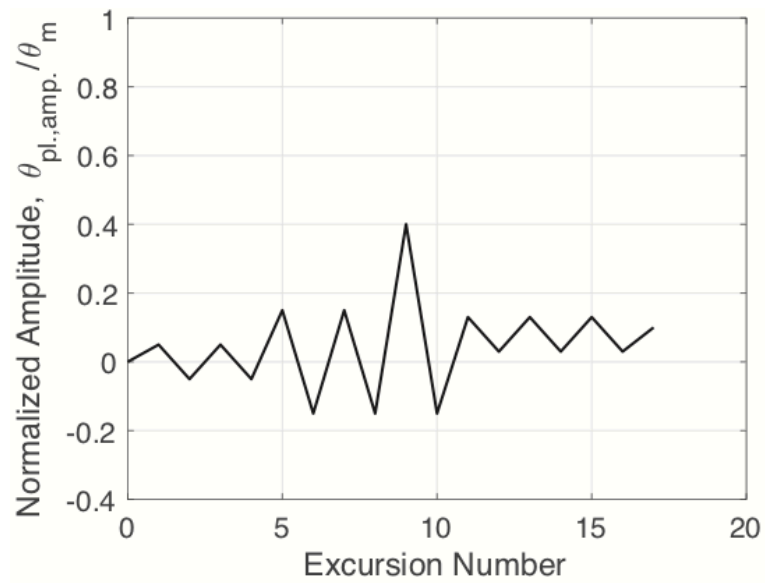

(a)

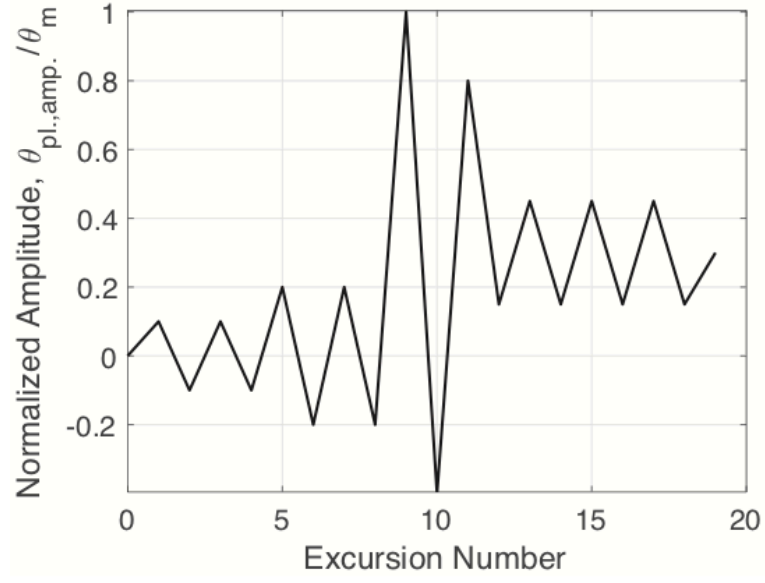

(c)

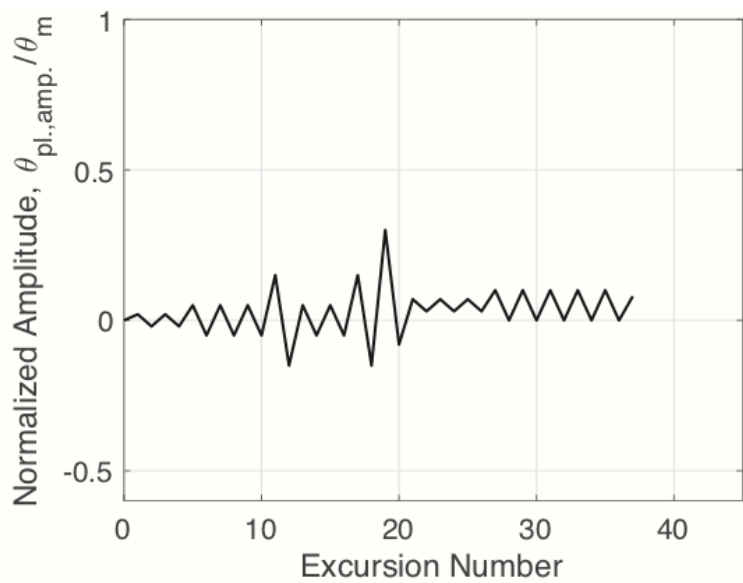

(b)

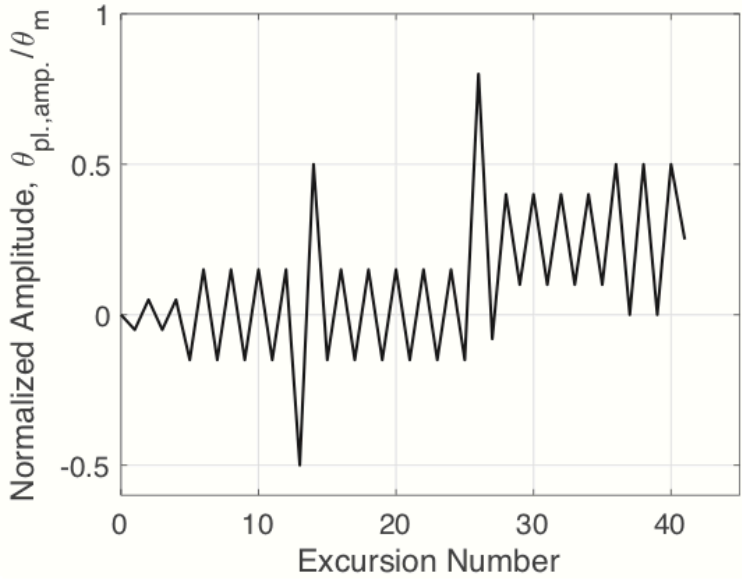

(d)

Figure 14. Proposed loading protocols for collapse modeling of steel columns - horizontal axis: excursion 
number; vertical axis: normalized plastic deformation amplitude.



Referring to Figure 14, if a steel column does not lose at least $50 \%$ of its load carrying capacity after the completion of the collapse-consistent load protocol, then this should be repeated with a residual offset. An illustrative example is shown in the subsequent section. From the same figure, slender columns $\left(27<D / t \leq 40,35<h / t_{w} \leq 55\right)$, typical in low-rise steel MRFs, are imposed to lateral drift demands dominated by a large cycle that tends to create appreciable mean deformations due to P-Delta effects. On the other hand, steel columns with relatively compact cross-sections (i.e., $20 \leq D / t \leq 27,16 \leq h / t_{w} \leq 35$ ) typically exhibit a single large excursion under a near-fault ground motion (see Figure 14a). Such columns are common in long-period steel MRFs and the above characteristic is often observed in their near-fault response (Alavi and Krawinkler 2004). Figures 14b and 14d suggest that mean effects are less pronounced in the development of collapse-consistent loading protocols representing long-duration records. However, the number of inelastic cycles in this case is much larger than that seen in near-fault records. Steel columns with stocky cross-sections $\left(D / t<20, h / t_{w}<16\right)$ experience negligible cyclic deterioration in their flexural strength even at large inelastic lateral drift demands (Newell and Uang 2008; Elkady and Lignos 2018b). In this case $\theta_{m}$ (see Figure 10b) cannot be practically obtained through a standard monotonic test due to the immoderate actuator stroke demands needed. A default, $\theta_{m}$ value of $0.08 \mathrm{rad}$ may be considered in this case. Beyond these rotation demands, steel MRFs typically experience structural collapse due to P-Delta effects (Ibarra and Krawinkler 2005; Elkady and Lignos 2015b). The above protocols have been implemented in a Matlab routine. They are made publicly available through the GitHub repository (https://github.com/dlignos/Collapse_Consistent_Protocols).

\section{ILLUSTRATION OF COLLAPSE-CONSISTENT LOADING PROTOCOLS AND ASSESSMENT OF COLLAPSE BEHAVIOR OF STEEL COLUMNS}

In order to illustrate the potential use of the proposed collapse-consistent loading protocols for experimental testing of steel columns, a step-by-step example is presented in this section. The proposed protocols are defined for a $3875 \mathrm{~mm}$ long HSS300x9 steel column as part of a 4-story steel MRF building tested on a shake table (Suita et al. 2008; Lignos et al. 2013) through collapse under the unscaled JR Takatori record from the 1995 Kobe earthquake. This is a nearfault record. The steel column is made of BCR295 steel (nominal yield stress, $f_{y}=295 \mathrm{MPa}$ ) and $P_{g} / P_{y}=-0.10$. Referring to Equation (2), the estimated axial load variation due to the transient load in end columns in the primary loading plane (2-bay direction) is, $P_{t} / P_{y}=0.10$ and,$P_{c} / P_{y}=-0.20$ in tension and compression, respectively. During the shake table test, the steel column lost its axial load carrying capacity due to local buckling as shown in Figure 15a. the reader is referred to (Lignos et al. 2013; Kasai et al. 2016) for further information regarding the testing program specifics. In order to define the lateral loading protocol, the $\theta_{m}$ is estimated by means of continuum finite element (CFE) analysis. The CFE column model is developed in ABAQUS Version 6.14 (ABAQUS 2014) based on detailed modeling procedures discussed in Elkady and Lignos (2015a, 2018b). This analysis is shown in Figure 15c (noted as monotonic curve). In this case, $\theta_{m}=6 \% \mathrm{rad}$. This value is consistent with that predicted from empirical relationships for HSS columns (Lignos and Krawinkler 2010). Since the HSS column has a $D / t=33.3$, the collapse-consistent protocol shown in Figure 14c is used to evaluate the column's collapse performance. The denormalized protocol is shown in Figure $15 \mathrm{~b}$ in this case. The loading protocol is repeated three times with a residual offset after the end of Phases 1 
and 2 so as the steel column fully loses its lateral load resistance as shown in Figure 15c. A "virtual" test is also conducted with a symmetric cyclic lateral loading history. The results in terms of deduced moment-rotation relation are shown in Figure 15d. Superimposed in Figures $15 \mathrm{c}$ and $15 \mathrm{~d}$ are the measured results from the shake table experiment for the same column (Suita et al. 2008; Lignos et al. 2013).

Referring to Figure 15c, the predicted cyclic deterioration in flexural strength of the HSS column as determined by the collapse-consistent loading protocol is nearly the same with the one measured from the experiment even at large lateral drift demands (larger than 0.08rads). On the other hand, Figure $15 \mathrm{~d}$ indicates that the steel column lost most of its flexural resistance at a drift demand of about $4 \%$ when imposed to a symmetric cyclic lateral loading protocol. This is due to the large number of symmetric cyclic load reversals (above $1.5 \%$ lateral drift demand) that are not evident prior to structural collapse. The above observations have direct implications into current seismic assessment guidelines of new and existing structures by means of nonlinear static procedures. In particular, the ASCE 41 (ASCE 2017) component model backbones are all based on first-cycle envelope curves fitted to structural component test data obtained from symmetric cyclic loading histories. One such curve is shown in Figure 15d. When backbone curves are based on those shown in Figure 15d, then the anticipated seismic demands are not representative at incipient collapse. This has also direct implications for the adopted ASCE 41 acceptance criteria for structural components (ASCE 2017).

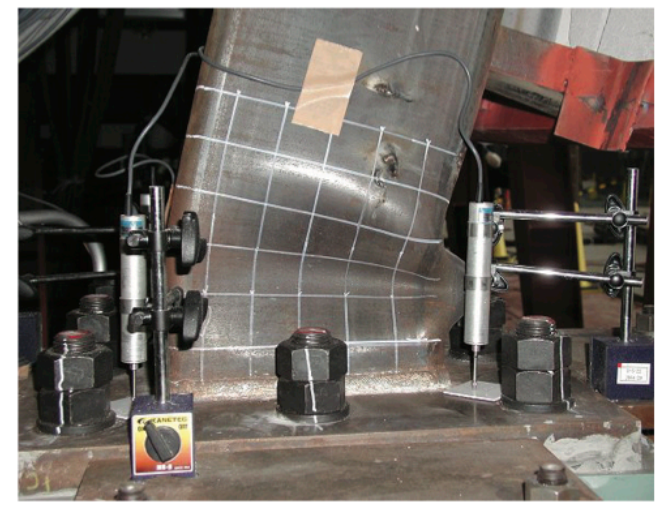

(a) Local buckling induced softening

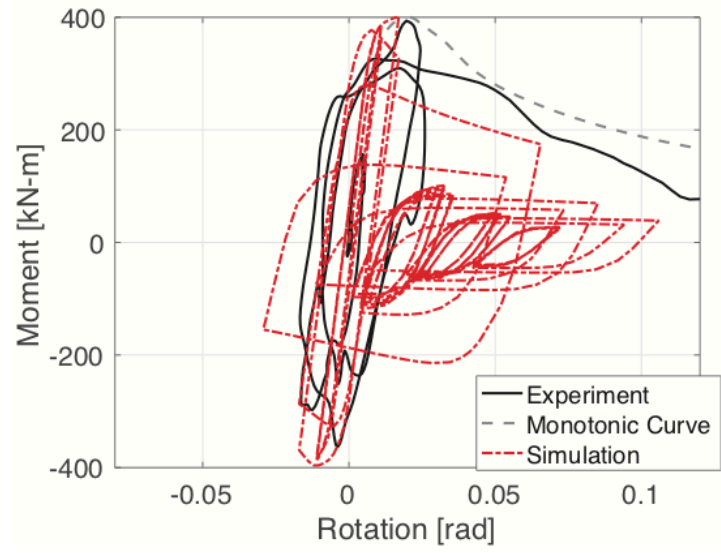

(c) Prediction with collapse-conistent protocol

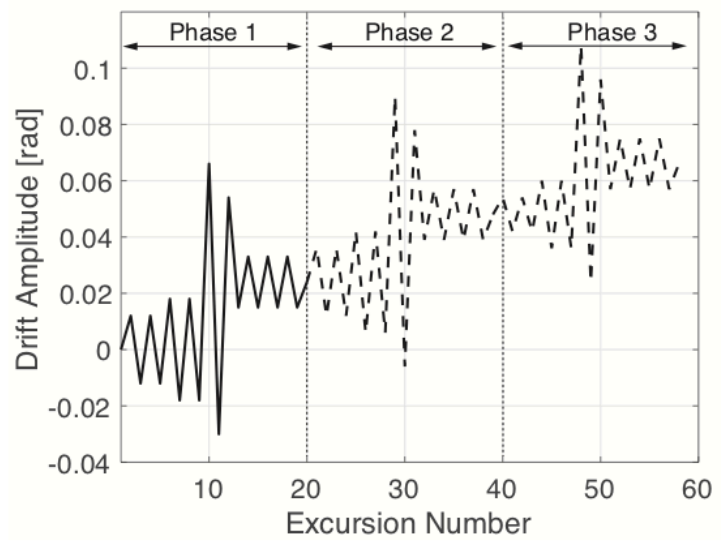

(b) Collapse-consistent loading history

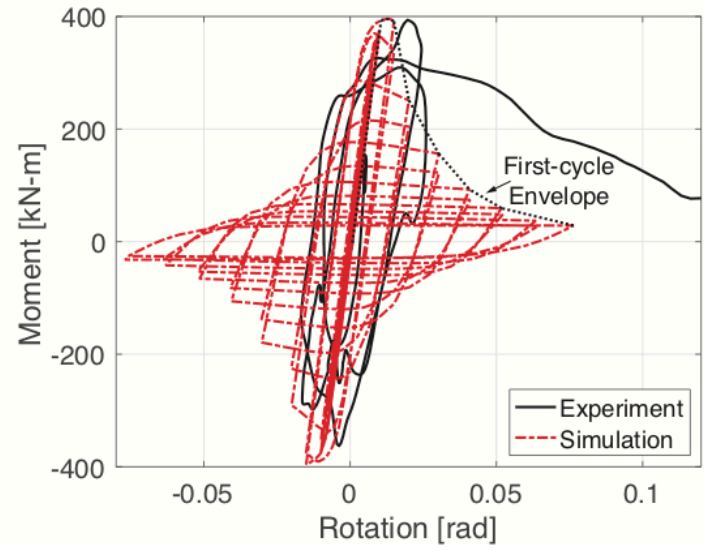

(d) Prediction with symmetric-cyclic protocol

Figure 15. Comparison of moment rotation diagrams of the first-story interior column top end of the 4story steel building tested at E-Defense (Image courtesy of the late Prof. H. Krawinkler; data from Kasai et al. 2016).

\section{CONCLUSIONS AND RECOMMENDATIONS}

This paper summarized the comprehensive development of dual-parameter collapse-consistent loading histories for experimental testing of steel columns under cyclic loading. The primary failure mode in steel columns is local 
buckling-induced softening. The developed protocols reflect the characteristics of the respective ground motion type (near-fault versus long-duration) as well as the column and building geometric properties. A distinction is made for end (exterior) and interior columns within the same building story. Depending on the building height, the former may experience large axial load variations due to dynamic overturning effects; while the latter typically experience constant compressive axial load coupled with lateral drift demands. The loading protocols are developed based on concepts of cumulative damage effects and statistical observations from rigorous nonlinear response history analyses (NRHA) through collapse based on more than 80 steel MRF archetypes designed in highly seismic regions. It was shown that The developed protocols are expressed as a function of the ultimate deformation capacity, $\theta_{m}$, which can be directly computed based on a standard monotonic column test. This capacity is defined as the deformation at which the column's flexural strength drops, for the first time, below $50 \%$ of the peak load. Alternatively, empirical formulations derived from experimental data may be used to compute $\theta_{m}$.

The maximum axial load variation, $P / P_{y}$ within an end MRF column typically ranges from $P_{c} / P_{y} \sim-0.4$ to -0.5 (in compression) to $P_{t} / P_{y} \sim 0.1$ to 0.2 (in tension) in mid- to high-rise steel MRF buildings. A much smaller variation is expected in low-rise steel MRF columns (i.e., $P_{c} / P_{y} \sim-0.1$ to -0.2 to $P_{t} / P_{y} \sim 0$ to 0.05 ). Such variation can be predicted based on an analytically derived expression or by standard nonlinear static analysis based on a first-mode lateral load distribution. The column axial load variation is characterized by three distinct ranges for steel MRF columns experiencing modest axial load demands, namely Range I: pre-buckling; Range II: post-buckling associated with a continuous growth of the column's web and/or flange local buckling; Range III local buckling size stabilization. A fourth range exists in which a steel column loses its axial load carrying capacity due to rapid progression of axial shortening. The above ranges are fully dependent of a column's cumulative plastic rotation and they can be expressed as a function of a column's deteriorating characteristics that are uniquely defined from a standard monotonic test.

A column's plastic rotation amplitude, $\theta_{p l, a m p}$ is dependent on the steel MRF height and column's local slenderness. Stockier columns in taller steel MRFs experience somewhat smaller lateral drift demands than slender columns in low-rise buildings prior to collapse. The reason is that tall steel MRFs are governed by P-Delta effects. Steel columns subjected to long-duration records would collapse at smaller lateral drift demands than columns subjected to nearfault records due to cyclic strength and stiffness deterioration prior to structural collapse.

Mean (residual) effects due to asymmetric lateral loading are significant regardless of the ground motion characteristics. This is to be expected for low-probability of occurrence seismic events due to ratcheting (frame drifting in one loading direction). Flexible steel MRF buildings are more likely to collapse than to experience large residual deformations due to their sensitivity to P-Delta effects. The first story steel MRF column mean $\theta_{p l, \text {,res. }}$ demands under long duration ground motions are, on average, about one third smaller than those seen under near-fault ground motions. This is in part attributed to the long-period pulse of near-fault ground motions that typically imposes structures into large lateral deformation demands.

The median cumulative plastic rotation demands, $\sum \theta_{p l}^{i}$. of columns in low-rise steel MRF buildings subjected to long-duration ground motions are, on average, three to six times larger than those under near-fault ground motions prior to collapse. This is due to the large number of inelastic deformation cycles contained within a long-duration record. Such differences practically diminish in long-period structures since they experience few large inelastic cycles. This should be further evaluated for long-duration ground motions recorded on soft soils. Although small inelastic deformation excursion ranges (i.e., 0-0.02rads) observed in long-duration ground motions are not expected to cause considerable in-cycle strength deterioration, their large number may cause ultra-low cycle fatigue. Their influence on the column axial shortening and unloading stiffness deterioration may also be significant.

Through a direct comparison with results from full-scale shake table collapse tests of a 4-story steel MRF building it was found that routinely used symmetric loading histories provide insufficient information regarding the deteriorating characteristics of steel columns prior to structural collapse.

\section{ACKNOWLEDGMENTS}

This study is based on work supported by Nippon Steel Corporation in Japan. This financial support is gratefully acknowledged. The main conclusions and recommendations are those of the authors and do not necessarily reflect those of the sponsors. The authors sincerely thank Prof. Kazuhiko Kasai for sharing the deduced moment-rotation data 
of the steel columns as part of the E-Defense shake table collapse experiment conducted in 2007 in Japan.

\section{REFERENCES}

ABAQUS. ABAQUS/CAE User's Guide version 6.14. Dassault Systèmes Simulia Corporation, Providence, RI., 2014

Adam, C., and Jäger, C. Seismic collapse capacity of basic inelastic structures vulnerable to the P-delta effect. Earthquake Engineering \& Structural Dynamics, 2012; 41(4), 775-793.

AISC. Seismic provisions for structural steel buildings, ANSI/AISC 341-10. Seismic Provisions, American Institute for Steel Construction, Chicago, IL., 2010.

Alavi, B., and Krawinkler, H. Behavior of moment-resisting frame structures subjected to near-fault ground motions." Earthquake Engineering \& Structural Dynamics, 2004; 33(6), 687-706.

Architectural Institute of Japan. Japanese architectural standard specification JASS 6 steel work. Architectural Institute of Japan (AIJ), Tokyo, Japan; 1996.

ASCE. Minimum design loads for buildings and other structures. American Society of Civil Engineers, Reston, Virginia, USA., 2016.

ASCE. Seismic evaluation and retrofit of existing buildings. American Society of Civil Engineers, Reston, Virginia., 2017.

Baker, J. Conditional Mean Spectrum: Tool for ground-motion selection. ASCE Journal of Structural Engineering, 2005; 137(3), 322-331.

BCJ. The building standard law of Japan. Codes and Standards, Building Center of Japan, Tokyo, Japan, 2011.

CESMD. Center for Engineering Strong Motion Data. 2012; <https://www.strongmotioncenter.org/> (Nov. 6, 2017).

Chiou, B., Darragh, R., Gregor, N., and Silva, W. NGA project strong-motion database. Earthquake Spectra, 2008; 24(1), 23-44.

Coffin, L. F. Jr. A study of the effects of cyclic thermal stresses on a ductile metal. Trans. ASME, 1954; 76, 931-950.

Elkady, A., and Lignos, D. G. Modeling of the composite action in fully restrained beam-to-column connections: implications in the seismic design and collapse capacity of steel special moment frames. Earthquake Engineering \& Structural Dynamics, 2014; 43(13), 1935-1954.

Elkady, A., and Lignos, D. G. Analytical investigation of the cyclic behavior and plastic hinge formation in deep wideflange steel beam-columns. Bulletin of Earthquake Engineering, 2015a; 13(4), 1097-1118.

Elkady, A., and Lignos, D. G. Effect of gravity framing on the overstrength and collapse capacity of steel frame buildings with perimeter special moment frames. Earthquake Engineering \& Structural Dynamics, 2015b; 44(8), 1289-1307.

Elkady, A., and Lignos, D. G. Development of bidirectional cyclic lateral loading protocols for experimental testing of steel wide-flange columns. Proceedings 3rd Huixian International Forum on Earthquake Engineering for Young Researchers, University of Illinois, Urbana-Champaign, USA., 2017.

Elkady, A., and Lignos, D. G. Full-scale testing of deep wide-flange steel columns under multiaxis cyclic loading: Loading sequence, boundary effects, and lateral stability bracing force demands. ASCE Journal of Structural Engineering, 2018a; 144(2), 04017189-1-15.

Elkady, A., and Lignos, D., G. Improved seismic design and nonlinear modeling recommendations for wide-flange 
steel columns. ASCE Journal of Structural Engineering, 2018b; 144(9), 04018162.

FEMA. Quantification of building seismic performance factors, Report FEMA-P695. Federal Emergency Management Agency (FEMA), Washington, DC., 2009a.

FEMA. Effects of strength and stiffness degradation on seismic response. Federal Emergency Management Agency (FEMA), Washington, DC., 2009b.

FEMA. Seismic performance assessment of buildings Volume 1 - Methodology. Federal Emergency Management Agency (FEMA), Washington, DC., 2012.

Gupta, A., and Krawinkler, H. Dynamic P-Delta effects for flexible inelastic steel structures. ASCE Journal of Structural Engineering, 2000a; 126(1), 145-154.

Gupta, A., and Krawinkler, H. Behavior of ductile SMRFs at various seismic hazard levels. ASCE Journal of Structural Engineering, 2000b; 126(1), 98-107.

Hartloper, A., and Lignos, D. G. Updates to the ASCE-41-13 provisions for the nonlinear modeling of steel wideflange columns for performance-based earthquake engineering. Proceedings 8th European Conference on Steel and Composite Structures, Ernst \& Sohn, Copenhagen, Denmark., 2017.

Hasegawa, T., Takahashi, K., Seki, M., Nagao, T., Mukai, Y., and Hukuda, K. Comparison between seismic performance of U.S. steel perimeter and Japanese special moment resisting frames (Part1-3). Architectural Institute of Japan, Japan, 1998; 325-328.

Haselton, C. B., Liel, A. B., Lange, S. T., and Deierlein, G. G. Beam-Column element model calibrated for predicting flexural response leading to global collapse of RC frame buildings. Pacific Earthquake Engineering Research Center (PEER), Berkeley, CA, USA, 2008; Report No. 152.

Hwang, S.-H., and Lignos, D. G. Earthquake-induced loss assessment of steel frame buildings with special moment frames designed in highly seismic regions. Earthquake Engineering \& Structural Dynamics, 2017; 46(13), 2141-2162.

Ibarra, L. F., and Krawinkler, H. Global collapse of frame structures under seismic excitations, The John A. Blume Earthquake Engineering Center, Stanford University, Stanford, CA. 2005; Report No. 152.

Ibarra, L. F., Medina, R. A., and Krawinkler, H. Hysteretic models that incorporate strength and stiffness deterioration. Earthquake Engineering \& Structural Dynamics, 2005; 34(12), 1489-1511.

Inamasu, H., Kanvinde, A. M., and Lignos, D. G. Seismic stability of wide-flange steel columns interacting with embedded column base connections. ASCE Journal of Structural Engineering, 2019; (accepted).

Inoue, K., Higashi, K., Ogawa, K., Tada, M., and Hasegawa, T. Earthquake response of structural members of rigid frames with RHS columns (Part 1-3). Architectural Institute of Japan (AIJ), Japan., 1995.

Kasai, K., Nam, T.-T., and Maison, B. F. Structural collapse correlative analysis using phenomenological fiber hinge elements to simulate two-directional column deteriorations. Earthquake Engineering \& Structural Dynamics, 2016; 45(10), 1581-1601.

Krawinkler, H. Cyclic loading histories for seismic experimentation on structural components. Earthquake Spectra, 1996; 12(1), 1-12.

Krawinkler, H. Loading histories for cyclic tests in support of performance assessment of structural components. 3rd International Conference on Advances in Experimental Seismic Engineering, Pacific Earthquake Engineering Research Center Annual Conference (PEER), San Francisco, CA., 2009.

Krawinkler, H., Gupta, A., Medina, R. A., and Luco, N. Development of loading histories for testing of steel beam- 
to-column assemblies. Federal Emergency Management Agency (FEMA), Washington, DC., 2000a.

Krawinkler, H., Parisi, F., Ibarra, L. F., Ayoub, A., and Medina, R. A. Development of a testing protocol for woodframe structures. Concortium of Universities for Research in Earthquake Engineering, Richmond, CA, USA, $2000 \mathrm{~b}$.

Krawinkler, H., Zohrei, M., Irvani, B. L., Cofie, N., and Tamjed, H. H. Recommendation for experimental studies on the seismic behavior of steel components and materials. The John A. Blume Earthquake Engineering Center, Stanford University, Stanford, CA., 1986; Report No. 61.

Krishnan, S. Modified elastofiber element for steel slender column and brace modeling. ASCE Journal of Structural Engineering, 2010; 136(11), 1350-1366.

Lignos, D. G., Hartloper, A., Elkady, A., Deierlein, G. G., and Hamburger, R. O. Proposed updates to the ASCE 41 nonlinear modeling parameters for wide-flange steel columns in support of performance-based seismic engineering. ASCE Journal of Structural Engineering, 2019; 145(9), 04019083.

Lignos, D. G., Hikino, T., Matsuoka, Y., and Nakashima, M. Collapse assessment of steel moment frames based on E-Defense full-scale shake table collapse tests. ASCE Journal of Structural Engineering, 2013; 139(1), 120-132.

Lignos, D. G., and Krawinkler, H. A steel database for component deterioration of tubular hollow square steel columns under varying axial load for collapse assessment of steel structures under earthquakes. Proceedings 7th International Conference on Urban Earthquake Engineering (7CUEE), CUEE, Tokyo Institute of Technology, Tokyo, Japan, 2010.

Lignos, D. G., and Krawinkler, H. Deterioration modeling of steel components in support of collapse prediction of steel moment frames under earthquake loading. ASCE Journal of Structural Engineering, 2011; 137(11), 1291-1302.

Lignos, D. G., and Krawinkler, H. Development and utilization of structural component databases for performancebased earthquake engineering. ASCE Journal of Structural Engineering, 2013; 139(8), 1382-1394.

Lignos, D., G., Krawinkler, H., and Whittaker, A., S. Prediction and validation of sidesway collapse of two scale models of a 4-story steel moment frame. Earthquake Engineering \& Structural Dynamics, 2011; 40(7), 807-825.

Lignos, D. G., Putman, C., and Krawinkler, H. Application of simplified analysis procedures for performance-based earthquake evaluation of steel special moment frames. Earthquake Spectra, 2015; 31(4), 1949-1968.

Maison, B. F., and Speicher, M. S. Loading protocols for ASCE 41 backbone curves. Earthquake Spectra, 2016; 32(4), $2513-2532$.

Manson, S. S. Behavior of materials under conditions of thermal stress., 1954.

Mavroeidis, G. P., and Papageorgiou, A. S. A mathematical representation of near-fault ground motions. Bulletin of the Seismological Society of America, 2003; 93(3), 1099-1131.

Mckenna, F. T. Object-oriented finite element programming: frameworks for analysis, algorithms and parallel computing. PhD Dissertation, University of California, Berkeley, CA., 1997.

Mergos, P. E., and Beyer, K. Loading protocols for European regions of low to moderate seismicity. Bulletin of Earthquake Engineering, 2014; 12(6), 2507-2530.

Miner, M. A. Cumulative damage in fatigue. Journal of Applied Mechanics, 1945; 12(3), A159-A164.

Nakashima, M., Roeder, C., W., and Maruoka, Y. Steel moment frames for earthquakes in United States and Japan. ASCE Journal of Structural Engineering, 2000; 126(8), 861-868.

Newell, J., and Uang, C.-M. Cyclic behavior of steel wide-flange columns subjected to large drift. ASCE Journal of 
Structural Engineering, 2008; 134(8), 1334-1342.

NIST. Evaluation of the FEMA P-695 methodology for quantification of building seismic performance factors. National Institute of Standards and Technology (NIST), U.S. Department of Commerce, Gaithersburg, Maryland, USA., 2009.

NIST. Recommended modeling parameters and acceptance criteria for nonlinear analysis in support of seismic evaluation, retrofit, and design. National Institute of Standards and Technology, Gaithersburg, MD., 2017.

Nojavan, A., Schultz, A. E., Haselton, C., Simathathien, S., Liu, X., and Chao, S.-H. A new data set for full-scale reinforced concrete columns under collapse-consistent loading protocols. Earthquake Spectra, 2015; 31(2), 12111231.

Okazaki, T., Lignos, D. G., Midorikawa, M., Ricles, J. M., and Love, J. Damage to steel buildings observed after the 2011 Tohoku-Oki earthquake. Earthquake Spectra, 2013; 29(S1), S219-S243.

Ozkula, G., Harris, J., and Uang, C.-M. Observations from cyclic tests on deep, wide-flange beam-columns. AISC Engineering Journal, 2017; (1), 16.

PEER/ATC. Guidelines for performance-based seismic design of Tall Buildings. Pacific Earthquake Engineering Research Center (PEER), University of California at Berkeley, Berkeley, CA, USA., 2010.

Ramirez, C. M., and Miranda, E. Significance of residual drifts in building earthquake loss estimation. Earthquake Engineering \& Structural Dynamics, 2012; 41(11), 1477-1493.

Richards, P. W., and Uang, C.-M. Testing protocol for short links in eccentrically braced frames. Journal of Structural Engineering, 2006; 132(8), 1183-1191.

Ruiz-García, J., and Miranda, E. Evaluation of residual drift demands in regular multi-storey frames for performancebased seismic assessment. Earthquake Engineering \& Structural Dynamics, 2006; 35(13), 1609-1629.

Sivaselvan, M. V. Hysteretic models with stiffness and strength degradation in a mathematical programming format. International Journal of Non-Linear Mechanics, 2013; 51, 10-27.

Suita, K., Suzuki, Y., and Takahashi, M. Collapse behavior of an 18-story steel moment frame during a shaking table test. International Journal of High-Rise Buildings, 2015; 4(3), 171-180.

Suita, K., Yamada, S., Tada, M., Kasai, K., Matsuoka, Y., and Sato, E. Results of recent E-Defense tests on full-scale steel buildings: Part 1 - Collapse experiment on 4-story moment frame. Proceedings ASCE Structures Congress, Vancouver, Canada, 2008.

Suzuki, Y. Earthquake-induced collapse of steel moment resisting frames with conventional and high-performance steel columns. PhD Dissertation, McGill University, Montreal, Quebec, Canada, 2019.

Suzuki, Y., and Lignos, D. G. Large scale collapse experiments of wide flange steel beam-columns. Proceedings 8th International Conference on Behavior of Steel Structures in Seismic Areas (STESSA), Shanghai, China, 2015.

Trifunac, M. D., and Brady, A. G. A study on the duration of strong earthquake ground motion. Bulletin of the Seismological Society of America, 1975; 65(3), 581-626.

Vamvatsikos, D., and Cornell, C. A. Incremental dynamic analysis. Earthquake Engineering \& Structural Dynamics, 2002; 31(3), 491-514.

Zareian, F., and Kanvinde, A. Effect of column-base flexibility on the seismic response and safety of steel momentresisting frames. Earthquake Spectra, 2013; 29(4), 1537-1559. 